\title{
On the One Hand and On the Other: The Effect of Embodying Balance and Uncertainty Orientation on the Confirmation Bias
}

Jeffrey Rotman, The University of Western Ontario

Supervisor: Dr. Richard Sorrentino, The University of Western Ontario

A thesis submitted in partial fulfillment of the requirements for the Master of Science degree in Psychology

(C) Jeffrey Rotman 2012

Follow this and additional works at: https://ir.lib.uwo.ca/etd

Part of the Social Psychology Commons

\section{Recommended Citation}

Rotman, Jeffrey, "On the One Hand and On the Other: The Effect of Embodying Balance and Uncertainty Orientation on the Confirmation Bias" (2012). Electronic Thesis and Dissertation Repository. 675. https://ir.lib.uwo.ca/etd/675

This Dissertation/Thesis is brought to you for free and open access by Scholarship@Western. It has been accepted for inclusion in Electronic Thesis and Dissertation Repository by an authorized administrator of Scholarship@Western. For more information, please contact wlswadmin@uwo.ca. 
ON THE ONE HAND AND ON THE OTHER:

THE EFFECT OF EMBODYING BALANCE AND UNCERTAINTY ORIENTATION ON THE CONFIRMATION BIAS

(Uncertainty Orientation Embodiment and the Confirmation Bias)

(Thesis format: Monograph)

by

Jeff $\underline{\text { Rotman }}$

Graduate Program in Psychology

A thesis submitted in partial fulfillment

of the requirements for the degree of Master of Science

The School of Graduate and Postdoctoral Studies

The University of Western Ontario

London, Ontario, Canada

(C) Jeff Rotman 2012 
THE UNIVERSITY OF WESTERN ONTARIO

School of Graduate and Postdoctoral Studies

CERTIFICATE OF EXAMINATION

$\underline{\text { Supervisor }}$

Dr. Richard Sorrentino

Supervisory Committee

Dr. Clive Seligman $\underline{\text { Examiners }}$

Dr. James Olson

Dr. Chris Roney

Dr. Clive Seligman

The thesis by

\title{
Jeff Daniel Rotman
}

entitled:

\section{On the One Hand and On the Other: The Effect of Embodying Balance and Uncertainty Orientation on the Confirmation Bias}

\author{
is accepted in partial fulfillment of the \\ requirements for the degree of \\ Master of Science
}




\begin{abstract}
The moderating effects of embodied cognition and uncertainty orientation were examined in relation to the confirmation bias. Specifically, the alternate movement of both hands palms up, which often accompanies the expression "on the one hand, and on the other" relating to the weighing of an argument, was manipulated. Uncertainty orientation distinguishes between people who are uncertainty-oriented (UOs), that confront uncertainty with the intention of resolving it, and people who are oriented toward certainty (COs), in that they attempt to maintain certainty, by creating a predictable environment. A predicted significant interaction was found for attitude polarization and a marginal effect was found for selective exposure, but the latter was found only for women. Several other dependent measures did not yield predicted results. Nevertheless, the study does show a link between uncertainty orientation and embodiment effects. Implications are discussed.
\end{abstract}

Keywords: uncertainty orientation, embodied cognition, conceptual metaphor, confirmation bias, attitudes, motivation 


\section{Acknowledgments}

First and foremost, I would like to thank my supervisor, Dr. Richard Sorrentino for his guidance, input, insight, and time. I am extremely grateful for his encouragement, support, and training throughout the entire Master's program.

I would also like to thank my advisory committee, Dr. Clive Seligman, Dr. Jim Olson, and Dr. Chris Roney, for their time and valuable advice.

Thank you to my lab mate, Yang Ye, for his assistance throughout this and our other projects. I would also like to thank our lab's research assistants, Kaitlin Yu, Jonel Mendreu, Shelby Wilson, and Yixian Li, for their commitment to data collection on this project.

Thank you to my friends and family, especially my parents, Larry and Shelley, and my brothers Cary and Shael for their love, encouragement, and support throughout my education.

Lastly, to my girlfriend Michelle, your love and reassurance keeps me strong, inspired, and determined. Thank you for everything. 


\section{Table of Contents}

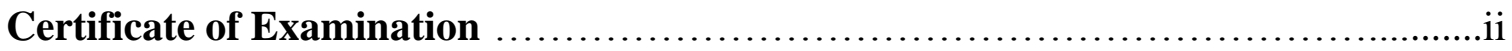

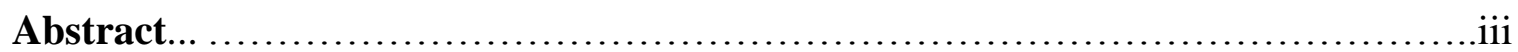

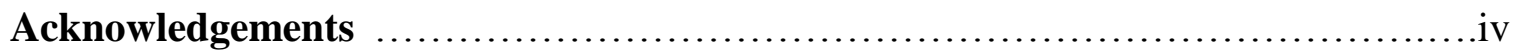

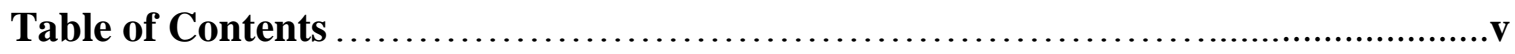

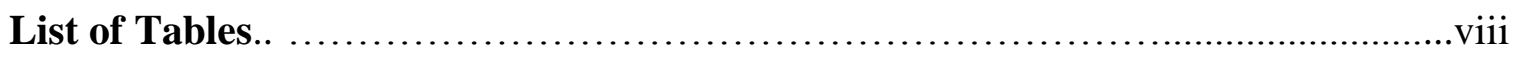

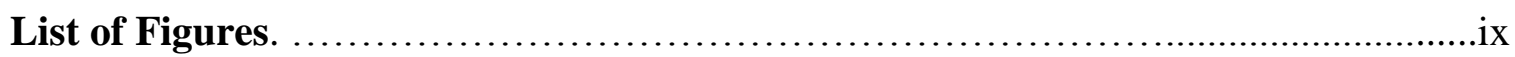

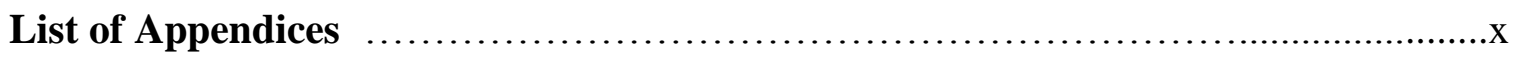

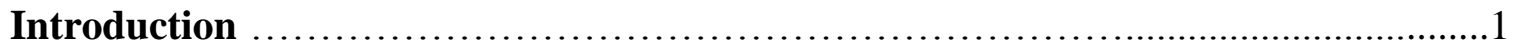

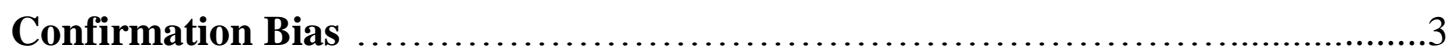

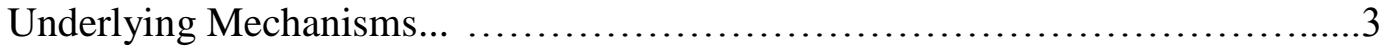

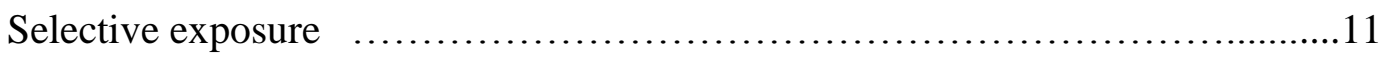

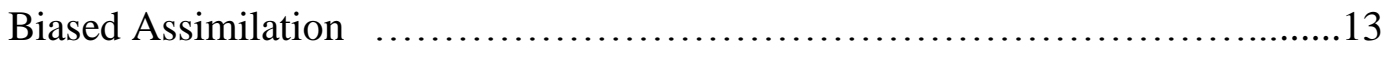

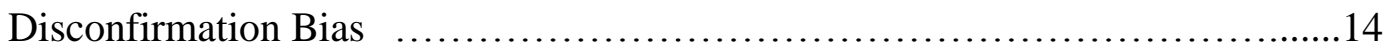

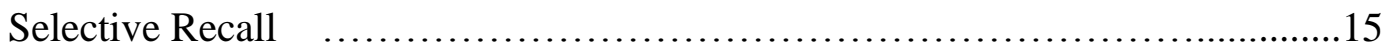

Attitude Polarization...... ................................................... 16

Individual Differences................................................ 17

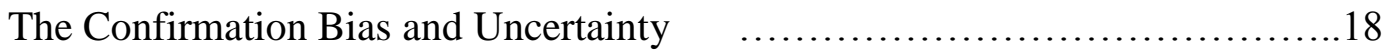

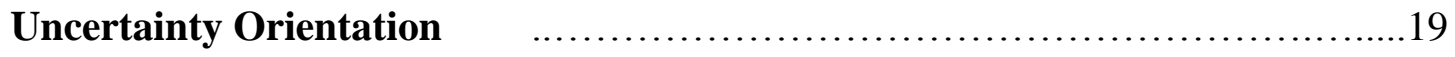

Uncertainty Orientation and Information Processing $\ldots \ldots \ldots \ldots \ldots \ldots \ldots \ldots \ldots . . . \ldots 21$

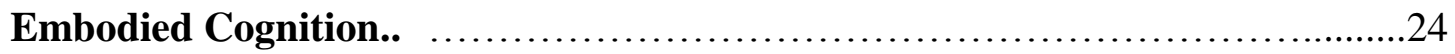

Embodiment and Conceptual Metaphor... ...............................28

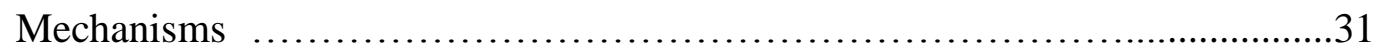


Individual Differences............................................... 33

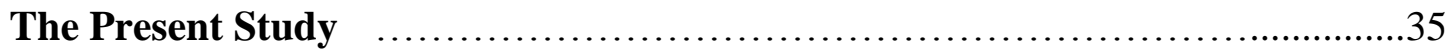

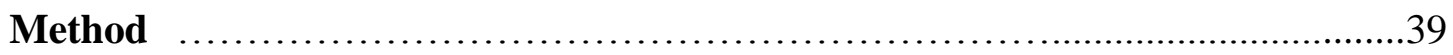

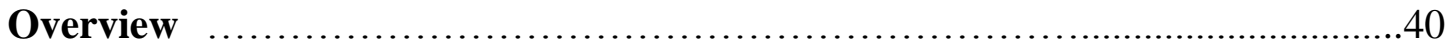

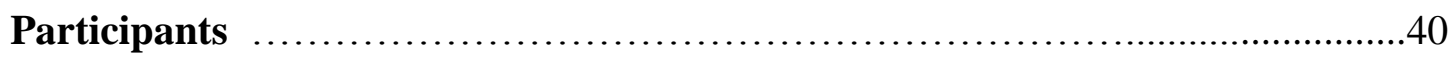

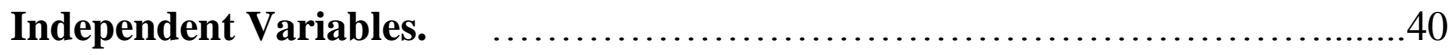

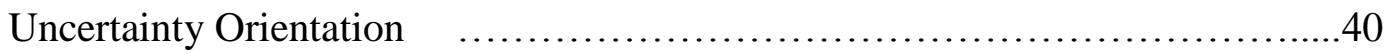

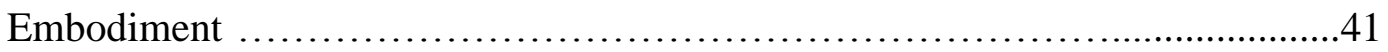

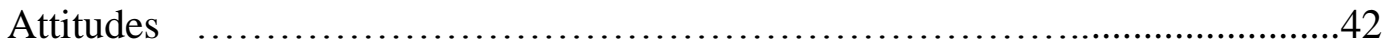

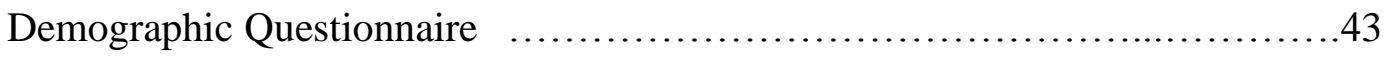

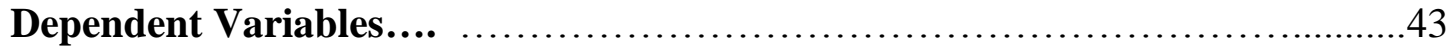

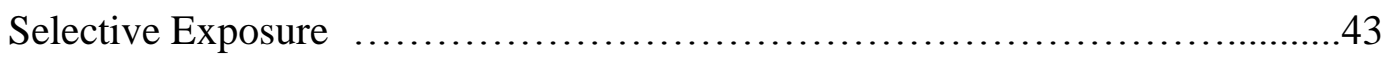

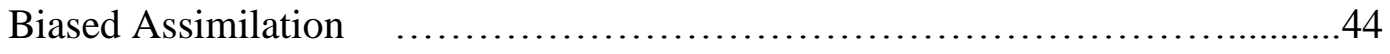

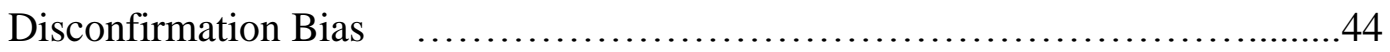

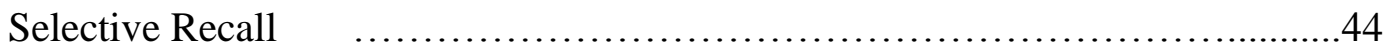

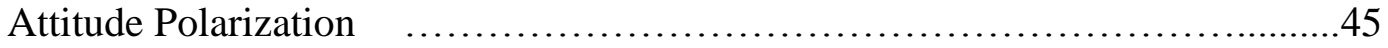

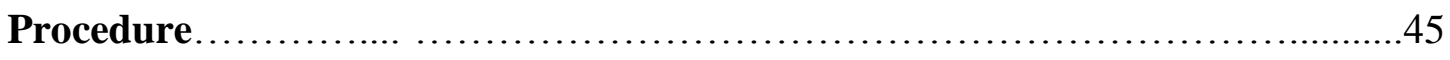

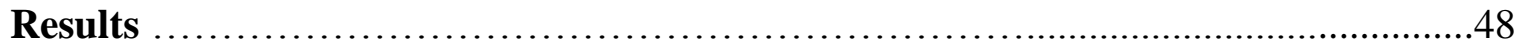

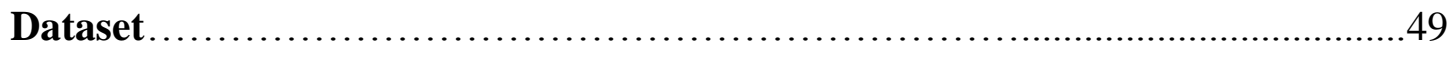

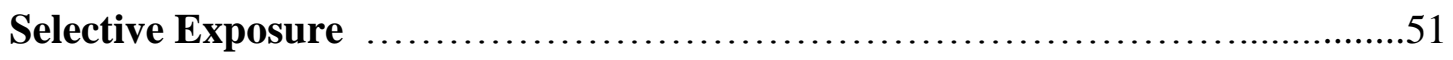

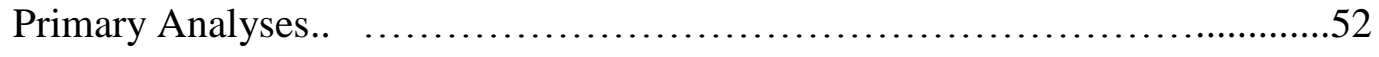

Additional Analyses.. . ...................................................53

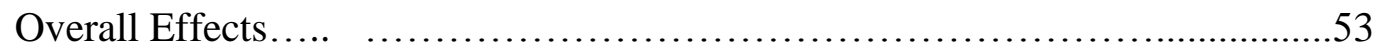




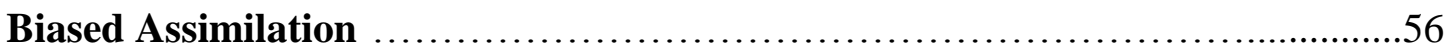

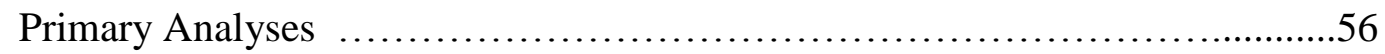

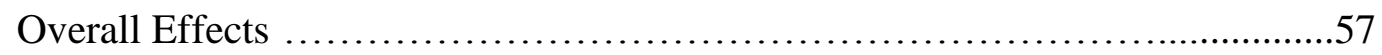

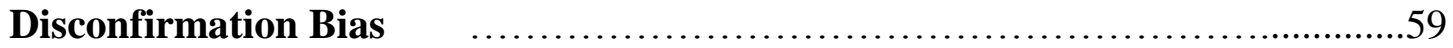

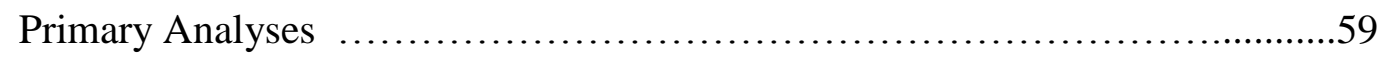

Additional Analyses $\quad$......................................................63

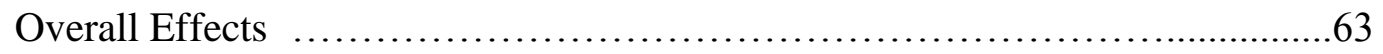

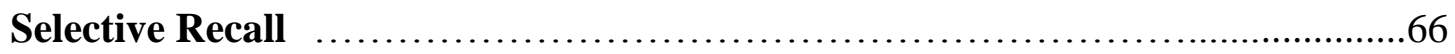

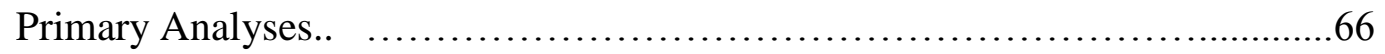

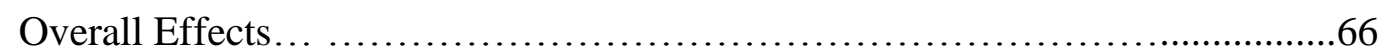

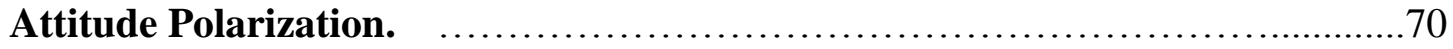

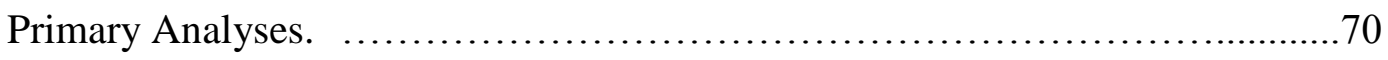

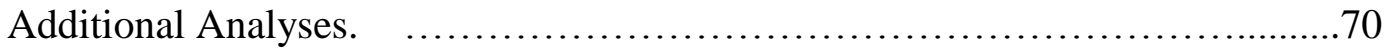

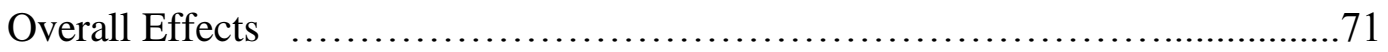

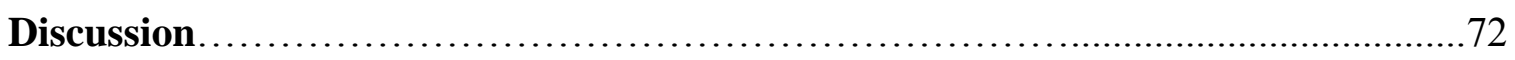

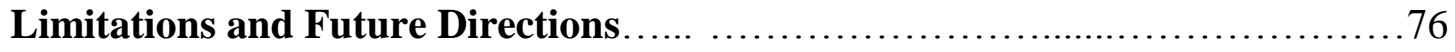

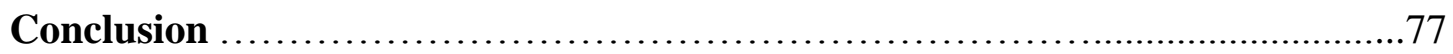

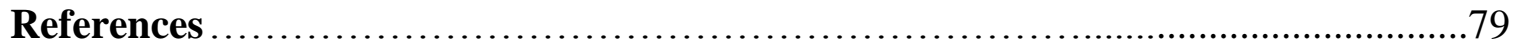

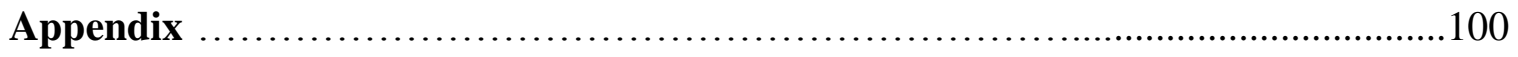

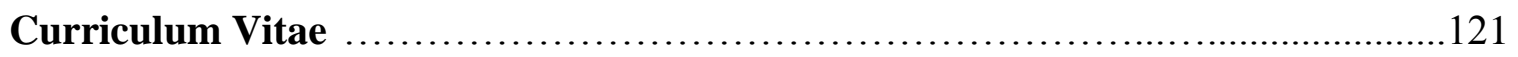




\section{List of Tables}

Table

Description

Page

$1 \quad$ Means and standard deviations for biased

58

assimilation across levels of uncertainty orientation and embodiment conditions

2 Means and standard deviations for disconfirmation

62 bias across levels of uncertainty orientation and embodiment conditions

3 Means and standard deviations for disconfirmation

65 bias across levels of uncertainty orientation and embodiment conditions, without employment equity

$4 \quad$ Means and standard deviations for selective recall across levels uncertainty orientation and embodiment conditions, without employment equity 


\section{List of Figures}

Figure

Description

Page

1 Selective exposure interaction between uncertainty

52 orientation and embodiment condition

2 Selective exposure interaction between uncertainty

55 orientation and embodiment condition for women

3 Biased assimilation interaction between uncertainty orientation and embodiment condition

$4 \quad$ Overall effects of biased assimilation

60

5

Disconfirmation bias interaction between uncertainty

61 orientation and embodiment condition

Disconfirmation bias interaction between uncertainty orientation and embodiment condition without employment equity

$7 \quad$ Selective recall interaction between uncertainty orientation and embodiment condition

Overall selective recall interaction

Attitude polarization interaction between uncertainty orientation and embodiment condition 


\section{List of Appendices}

Appendix

A nUncertainty, Thematic Apperception Test 100

$\begin{array}{lll}\text { B } & \text { Authoritarianism - F-Scale } & 101\end{array}$

C Demographics Questionnaire 104

$\begin{array}{ll}\text { D } 4 \text { x } 4 \text { Information Matrix } & 105\end{array}$

E List of Arguments For Each Topic 106

$\begin{array}{ll}\text { F } & 114\end{array}$

G Matrix with Embodiment Manipulation Prompt 115

$\begin{array}{ll}\mathrm{H} & 116\end{array}$

$\begin{array}{ll}\text { I Argument Rating Example } & 117\end{array}$

$\begin{array}{ll}\text { J Matrix Argument Selection } & 118\end{array}$

$\begin{array}{lll}\text { K } & 119\end{array}$

$\begin{array}{lll}\text { L Ethics Approval Form } & 120\end{array}$ 
INTRODUCTION 
The human understanding when it has once adopted an opinion draws all things else to support and agree with it. And though there be a greater number and weight of instances to be found on the other side, yet these it either neglects or despises, or else by some distinction sets aside or reject, in order that by this great and pernicious predetermination the authority of its former conclusion may remain inviolate.

Sir Francis Bacon, 1620

The understanding that our attitudes can have a biasing effect on information processing has a long history, as the above quotation would suggest. This biasing effect has been linked to many other processes in social psychology such as resistance to changing stereotypes (Allport, 1954; Sherman, Allen,\& Sacchi, 2012), the persistence of illusory correlations, (Chapman \& Chapman, 1967), self-fulfilling prophecies (Rosenhan, 1973), and self-verification (Swann, Pelham, Krull, \& Douglas, 1989). It has also been cited as a problem in economics and finance (Pompian, 2006), medicine (Nickerson, 1998), law and politics (Myers \& Lamm, 1976; Loftus, Greene,\& Doyle, 1989; Taber \& Lodge, 2006), real estate (Kempton, Alani, \& Chapman, 2002) and in scientific reasoning and methodology (Nickerson, 1998; Mahoney, 1977). Despite the pervasiveness of this psychological tendency and the understanding of factors that contribute to it, little research has investigated ways to lessen its effect.

The current research was conducted to examine the moderating effects of uncertainty-orientation and embodied cognition on this biasing effect of attitudes on information processing. In addition this research is designed to provide insights into the mechanisms of embodied cognition by examining individual differences. 


\section{The Confirmation Bias}

Underlying Mechanisms. Whether voting for a politician, deciding which car to buy, or determining if a criminal is guilty, the need to think critically, weigh evidence objectively, and make appropriate decisions permeates our daily lives and our most important responsibilities. However, these tasks are rendered difficult by a particularly powerful psychological phenomenon known as the confirmation bias. Klayman (1995) argued that there are about as many operational definitions of the term, confirmation bias, as there are studies that explore it. The confirmation bias, as it was initially conceived, is the tendency for people to seek evidence favouring one's already existing hypotheses (Wason, 1960). However, recent interpretations have used the confirmation bias to refer to a variety of behaviours such as searching for congruent information (Jonas, ShulzHardt, Frey,\& Thelen, 2001) or the tendency to interpret ambiguous evidence in favour of one's beliefs and to ignore or reinterpret evidence unfavourable to them (Nickerson, 1998; Perfors \& Navarra, 2009; Oswald \& Grosjean, 2004; Taylor \& Brown, 1988). Thus, the term confirmation bias is defined here as the seeking and interpreting of evidence in ways that confirm existing attitudes, beliefs or expectations (Nickerson, 1998; Taylor \& Brown, 1988).

It is important to note that the issues surrounding the operational definition of the term confirmation bias may be, at least in part, due to the distinction between motivated and unmotivated forms of the confirmation bias (Nickerson, 1998). Although this paper focuses primarily on the former, the latter should be addressed. People tend to search for and overweight positive confirmatory evidence even when there is no vested interest. For example, as early as 1956, Bruner, Goodnow, and Austin showed that participants would 
only search for examples that would provide instances if their hypothesis was correct. In Wason's (1960) 2-4-6 task, he showed further evidence of individuals only asking questions that were thought to yield positive answers. Further research (Mynatt, Doherty,\& Tweney, 1977; Wason, 1968) have showed that individuals do not only have an inclination to test positive-yielding questions, but also a bias in interpreting ambiguous answers that would yield a positive answer.

This more cognitive view has also been used to explain the motivated findings of the confirmation bias. Although early research regarding such reasoning took for granted that motivation may cause people to make decisions in a self-serving way (e.g. attribution theory; Weiner, 1972; Heider, 1958), this view came under attack during the cognitive revolution when it was suggested that many of the findings could be interpreted using strictly cognitive (and non-motivational) theory (Miller \& Ross, 1975; Bem, 1967; Nisbett \& Ross, 1980). As such, evidence that was purported to support motivated reasoning was simply recast as a function of biased information processing. Nisbett and Ross (1980) have argued that motivational commitment to strongly held beliefs tells us nothing about the precise cognitive mechanisms by which individuals seek and interpret evidence. Instead, Ross and colleagues (Nisbett \& Ross, 1980; Miller \& Ross, 1975; Ross, Lepper, \& Hubbard, 1975) argued for a purely information-processing explanation. Cognitive theorists argue that biases are the result of rational, but imperfect, inferential processes.

It should be noted here that under both the cognitive and motivational view, individuals are not intentionally choosing to be biased, but rather, the biases are often uncontrollable and unconscious. Similarly, even when individuals know about the 
potential of bias, it is difficult to know what the magnitude of the bias will be,and as such properly correcting for it is extremely challenging (Wilson, Centerbar, \& Brekke, 2002).

Under the cognitive view, people seek and interpret evidence due to cognitive biases and heuristics. Judgmental errors do not arise due to motivational or emotional reasons, but rather, they form primarily from non-motivational information processing strategies. For example, individuals search for consistent information because consistent information is more accessible or because people typically use a positive test strategy heuristic (Klayman \& Ha, 1987). For example, in one study (Snyder \& Swann, 1978) participants were asked to test whether a person was an introvert or an extrovert. They were allowed to select questions from a possible list that asked about introverted behaviours or extroverted behaviours. The results from this study and others (Devine, Hirt, \& Gehrke, 1990; Hodgins \& Zuckerman, 1993; Swann\& Read, 1981; Snyder, 1981) have demonstrated that individuals prefer to ask questions that are consistent with their hypotheses. For example, if asked to determine whether a person is an extrovert, participants prefer questions such as 'are you usually the initiator of forming new relationships' as opposed to 'do you usually go to movies alone.'

In 1979, Lord, Ross, and Lepper, ran an experiment with participants who had strong beliefs in favour of or against capital punishment. Each participant readdescriptions of two studies; one that confirmed their pre-existing beliefs about the deterrent efficacy of the death penalty and one that disconfirming their beliefs (counterbalanced). Participantsreada detailed account of each study's procedure and participants had to rate how well-conducted and convincing the research was. As predicted, both proponents and opponents of capital punishment rated attitude congruent 
results as more convincing whereas they reported the opposing studies as problematic in terms of methodology. Under a purely cognitive view, these results are interpreted such that individuals draw these conclusions not because of any inherent motivation but because they appear more plausible given one's prior beliefs, attitudes, and expectancies. This asymmetrical criteria for supportive and opposing information is then a function of the fact that people evaluate evidence as stronger if they believe them to be 'right,' (Lord, 1989), if it is processed more fluently due to familiarity (Whittlesea, 1993), or because it is difficult to gather information for multiple hypotheses at the same time (Tweney et al., 1983).

The cognitive view came under criticism with a return to a motivational perspective (Kunda, 1990; Sorrentino \& Higgins, 1986; Pyszczynski \& Greenberg, 1987; Baumeister \& Newman, 1994; Perkins, Farady, \& Bushey, 1991). Under this view, motivation affects reasoning by drawing on a biased set of cognitive processes; thus purporting the motivation versus cognition debate to be a false dichotomy. Rather than conceptualizing motivation and cognition as distinct processes, motivation can be seen as synergistic with cognition (Sorrentino \& Higgins, 1986; Kruglanski et al., 2002).Kunda (1990) suggested, "people rely on cognitive processes and representations to arrive at their desired conclusions, but motivation plays a role in determining which of these will be used on a given occasion" (p. 480). For example, individuals who have the motivation to be accurate will draw on processes that facilitate a correct conclusion, whereas individuals who have a motivation to arrive at a desired conclusion will draw on cognitive mechanisms that help facilitate that goal. In other words, as Bargh and colleagues (2001) noted, "however a goal is activated, either by conscious or 
nonconscious means, it will operate effectively to guide a person's goal-relevant cognition, affect, and behavior from that point on.” (p.1015).

Pyszcynski and Greenberg's (1987) biased hypothesis testing model is very similar but focuses on the self-serving aspect of biasing in which bias occurs at each stage of the testing sequence, such as the selection of the hypothesis, the search for evidence, the evaluation of evidence, and the amount of evidence one requires to make a conclusion. Indeed, Kunda (1990) argued that her paper is an extension of the biased hypothesis testing model but adds that other goals, such as the motive to be accurate (Kruglanski \& Freund, 1983; Johnston, 1996; Chaiken et al., 1989) can shape how information is searched.

Under this perspective, what motivation an individual has will affect the cognitive strategies one uses. For example, the work by Kruglanski and Freund (1983) demonstrates a good example of accuracy motivation. They showed that individuals who feared that their judgments would be evaluated for errors showed fewer errors due to primacy effects, ethnic stereotyping and anchoring. Additionally, Tetlock (1985) showed that individuals who had to justify their impressions of an essay writer in a typical attitude-attribution paradigm (Heider, 1958) were more likely to be sensitive to situational factors and thus showed a decrease in the fundamental attribution error effect. In addition, Trope and Liberman (1996) argue that general desire to reduce uncertainty is what motivates people to question and test their hypotheses, with larger levels of uncertainty leading to more diagnostic processing

With respect to the confirmation bias, a desired conclusion creates directional goals and will bias reasoning by affecting the information that becomes accessible, bias 
conclusions by determining when to stop searching for information, and bias inferential rules. In other words, motivation provides the initial trigger and a biased set of cognitive processes take over (Perkins, Faraday, and Bushey, 1991; Baumeister \& Newman, 1994). As such, people are more likely to recall specific details from memory and will be faster in their recall when motivated to do so (Sanitioso et al., 1990). Another conceptualization suggests that when motivated to agree with something, people essentially ask 'can I believe this?' which allows for a more permissive standard for evidence. However, when motivated to disagree with a hypothesis, people implicitly ask 'must I believe this?' and tend to search through as much evidence in order to disconfirm it (Dawson, Gilovich, \& Regan., 2002).

One of the main processes underlying this motivational bias is cognitive dissonance (Festinger, 1957; Kunda, 1990; Munro \& Ditto, 1997). Recent examinations of dissonance paradigms have revealed that dissonance occurs in response to a threat to the self or to one's self-consistency ${ }^{1}$ (Aronson, 1968; Cohen, Aronson, \& Steele, 2000; Steele, 1988; Tesser, 2000), As such the confirmation bias can also be seen as a function self-enhancing and self-protection motives (von Hippel, Laking, \& Shakarchi, 2005; Tesser, 2000; Tesser, Crepaz, Beach, Cornell, \& Collins, 2000). Cherished beliefs are often held as an important aspect of one's self (Cohen, Aronson, \& Steele, 2000; Skitka, Bauman, \& Sargis, 2005) and when presented with dissonant information, this creates a state of arousal. As such, people tend to neutralize these threats, reduce the dissonance, and restore consonance by evaluating information in a defensive and biased way

\footnotetext{
1 although a number of other models have been hypothesized to explain dissonance effects e.g.the Aversive Consequences Model (Cooper \& Fazio, 1984) or the Action-Orientation Model (Harmon-Jones, Gerdjikov,\& Harmon-Jones, 2008).
} 
(Pyszcynski \&Greenberg, 1987; Ditto \& Lopez, 1992; Dunning, Leuenberger \& Sherman, 1995). Because of this, one can protect against this threat through selfaffirmation (Steele, 1988; Sherman, Nelson,\& Steele, 2000). This perspective suggests that affirmation makes additional sources of the self accessible and subsequently reduces the need to defend it in a biased way. For example,Cohen, Aronson and Steele (2000) as well as Correl and colleagues (2004) showed that when individuals self-affirmed, by focusing on other important traits, they were more persuaded by information challenging their views than when they were not affirmed. Furthermore, Munro and Stansbury (2009) have shown that affirming individuals prior to giving them threatening information reduces their motivation to disconfirm it.

Thus two goals, accuracy and directionality are viewed as two important motives underlying information search. This tradeoff between accuracy and directional goals led to the idea that the confirmation bias is "motivated by the cost of inferential errors relative to the cost of information" (Trope \& Liberman, 1996, p.240). Thus, accuracy and directional bias are two coexisting properties, and how much one is motivated to avoid an accuracy error and how motivated an individual is to keep a consonant world view can be seen as two competing motivations.

Research has demonstrated (Tetlock, 1992; Trope \& Pomerantz, 1998; Jonas \& Frey, 2003) that by increasing the importance of a situation or of a decision, individuals will be more likely to focus on accuracy goals, and be less likely to exhibit a directional bias. Consider that in typical dissonance paradigms, attitude change does not reverse, it merely becomes weakened. Thus, it is suggested that when determining one's postdissonance attitude, people are motivated to be biased in their search for and overweight 
behaviour-congruent evidence. Note though that this search, although biased, is still a subset of all relevant evidence and beliefs, so that people can maintain what Pyszczynski \& Greenberg (1987) call an illusion of objectivity. Some evidence comes from research examining evaluations of others whereby participants were to play a history trivia game. Participants were then told about a person who received a perfect score on a prior task and were told that they were set to be their partner or their competitor. Participants who were set to have this person as a partner rated this person as being better at history than those who were set to have them as an opponent, presumably because in the former condition they wanted this target person to have high ability. However, it is important to note that even when the participants wanted this person to have low ability (e.g. in the competitor condition), participants still rated their ability level fairly high, suggesting that people are constrained by information and accuracy motives (Klein \& Kunda, 1989).

These theories have also received support from neuroscience. Research on what neural areas are associated with the confirmation bias showed that the regions activated were not associated with previously recognized cold reasoning (Westen, Blagov, Harenski, Kilts,\& Hamann, 2006). In this paper, participants were given threatening information about their preferred 2004 electoral candidate. Participants showed heightened activity in areas linked with emotion regulation (Oschner \& Gross, 2005). The authors suggest that motivated reasoning is distinct from other forms of reasoning. Additionally, work by Van Veen, Krug, Schooler and Carter (2009) has shown that these same areas were active during a cognitive dissonance task, and the amount of activation predicted the amount of attitude change. 
Although this section has dealt with the underlying mechanisms theorized to be responsible for the confirmation bias, the behavioural consequences have only been discussed in passing. Selective exposure, biased assimilation, a disconfirmation bias, attitude polarization and selective recall have all been linked to these processes. In the following sections, each of these behavioural effects will be elaborated upon.

Selective Exposure. The information age has drastically changed the way we get our information. On the one hand, it makes passive viewing of information (e.g. watching T.V.) less common and makes active exposure to information much easier. At any given moment, an individual can select from virtually limitless amounts of information, finding support for any hypothesis. Although some have hypothesized that an increase in open information will encourage political discussion and raise awareness of certain issues (Shah, Cho, Eveland \& Kwak, 2005), others suggest that it will lead to increased polarization of attitudes and the fragmentation of society (Sunstein, 2007; Evans, Bryson, \& DiMaggio, 2001; Jun, 2012).

This latter hypothesis stems from work on selective exposure. Selective exposure refers to the tendency for individuals to favour information that is congruent with one's attitudes and preferentially avoid dissonant information. This behaviour of seeking agreeable ideas is theorized to be a product of cognitive dissonance (Cotton, 1985; Olson \& Stone, 2005; Jonas, Schulz-Hardt,\& Frey, 2005; Mills, 1965). Under this view, people seek out consonant ideas in order to avoid challenging ideas that would create a dissonant state. The anticipation of incongruent evidence and thus cognitive dissonance motivates individuals to seek congruent information in an attempt to avoid dissonance. 
Additionally, work by Brannon, Tagler \& Eagly (2007) provided a series of studies revealing that attitude strength moderated selective exposure, with stronger attitudes providing a more extreme effect, presumably due to an increased motivation to prevent dissonance. The authors note that these results seem to conflict with those of Albarracin and Mitchell (2004) who showed that individuals who had high confidence and could successfully defend their attitudes were more likely to view counter-attitudinal information. However, Brannon and colleagues (2007) argue that while attitude strength and attitude confidence should correlate, no work has been done on this topic. Instead, it may be that there exists an important psychological difference between attitude strength and attitude confidence, such that individuals with strong attitude confidence do not fear oppositional information.

Work examining the effect of implicit and conscious attitudes has shown that they both predict selective exposure (Galdi, Gawronski, Arcuri \& Friese, 2012). However, whereas selective exposure has been correlated with explicit attitude strength, Galdi and colleagues (2012) found that the strength of automatic associations predicted selective exposure for those with weaker attitudes.

Researchers have also argued for the importance of accuracy motives, citing the importance of the outcome and the utility of the available information as moderating factors (Tetlock, 1992; Jonas, Schulz-Hardt, \& Frey, 2005; Jonas, Greenberg, \& Frey, 2003). For example, in a study by Jonas and Frey (2003), when participants were asked to take on the role of an advisor in helping another person make travel decisions they were more likely to be balanced when searching for information. Furthermore, additional analyses revealed that accuracy motivation partially mediated this effect. 
Overall, arecent meta-analysis (Hart et al., 2009) revealed a preference for congruent versus incongruent information across studies. As expected, selective exposure for congenial information was moderated by strength of attitude, the quality of the information, and the importance of the information.

Biased Assimilation. Research in social cognition has provided many examples in which prior information plays an important and powerful role in decision making (e.g. anchoring effects, Tversky \& Khaneman, 1974). Our ability to 'know' what things we will enjoy or agree with and what things we will dislike or disagree with is partially shaped by a behavioural tendency known as biased assimilation. This bias posits that individuals will interpret information in a way, such that it remains consistent with prior beliefs, attitudes and expectations.

While the Lord, Ross, and Lepper (1979) study depicted in the previous section provides one instance of this effect, it has been replicated in numerous other studies (e.g. Munro \& Ditto, 1997; Miller, McHoskey, Bane \& Dowd, 1993; Edwards \& Smith, 1996). For example, in one study by Taber \& Lodge (2006), which serves as part of the methodological basis for this project, subjects were asked to take part in a survey of public opinion. Their task was to evaluate two contemporary political issues; gun control and affirmative action. Participants were presented with a matrix of 16 hidden policy arguments via computer, which participants could view by clicking on them using a mouse. However, the arguments were labeled with the argument's position (political organizations that were in favour or against the issue). They were then allowed to view 8 of the 16 arguments with no time limit, but could not view the same argument twice. Participants who favoured gun control or affirmative action rated congruent arguments to 
their own opinions as stronger than incongruent arguments, while those opposed to gun control and affirmative action saw the arguments against the issue as stronger. The researchers also found effects for selective exposure, attitude polarization, biased assimilation, confirmation bias, and a disconfirmation bias.

Although a cognitive view hypothesizes biased information-processing due to over-generalizations and adaptive heuristics (Koehler, 1991; Lord \& Taylor, 2009), the motivational perspective argues that information that contradicts a pre-existing attitude produces negative arousal and subsequently produces motivation to reduce that dissonance (Festinger, 1957; Berkowitz \& Devine, 1989) and indeed subsequent studies have documented the role of negative arousal in the effect (Munro \& Ditto, 1997; Munro, Stansbury,\& Tsai, 2012). For example, Munro, Stansbury, and Tsai (2012), showed that by giving participants the opportunity to misattribute the negative affect felt when given attitude-incongruent scientific studies to 'non-optimal' room conditions or water that contained 'caffeine' (Zanna \& Cooper, 1974), it resulted in more positive ratings of the studies.

Disconfirmation Bias. Linked with biased assimilation, is a behavioural tendency to spend time and cognitive resources actively counterarguing attitudinally inconsistent information. For example, the participants in Lord, Ross, and Lepper's (1979) study were also asked to provide comments on their thoughts towards the congruent and incongruent studies. One participant who was pro-capital punishment addressing an anti-capital punishment study reported "there were too many flaws in the picking of the states and too many variables involved in the experiment as a whole" 
(p.2103); an anti-capital punishment person commenting on the same article stated "the murder rates climbed in all but two of the states after new laws were passed and no strong evidence to contradict the researchers was presented" (p. 2103).

Work by Edwards and Smith (1996) evaluated the disconfirmation bias in more detail, suggesting that when an argument is incongruent with prior beliefs, individuals will scrutinize the argument. This scrutinizing requires extensive cognitive processing, drawing from memory evidence against the argument as well as further attention to the logic and evidence of the argument itself. Additionally, the authors suggest that this scrutinization should be time consuming and result in more recalled material. Indeed, in a series of studies, the authors demonstrated that incongruent arguments resulted in longer processing and resulted in more arguments generated.

Selective Recall. Whether people are more likely to remember consistent or inconsistent information is still in contention (Strangor \& McMillan, 1992; Eagly, Chen, Chaiken, \& Shaw-Barnes, 1999). On the one hand, consistent information fits into an individual's schema and is therefore more likely to be integrated and more likely to be recalled (Oswald \& Grosjean, 2004). On the other hand, inconsistent information results in an expectancy violation which is immediately salient and results in increased elaboration if viewed as a threat on the self, as discussed above. A meta-analysis (Eagly, Chen, Chaiken, \& Shaw-Barnes, 1999) examining this process found evidence for both, and although memory was slightly improved for congenial information, the studies were quite mixed in their conclusions. Further analysis revealed a number of moderating variables. For example, higher attitude relevance correlated with a larger congeniality 
effect, whereas higher outcome relevance was associated with a weaker effect.

Additionally, more attitude-consistent information was remembered when it was delayed, than when tested immediately following exposure. Thus, while the overall effect of attitude on memory is towards attitude-consistent information, this behavioural effect is more varied and nuanced then the ones mentioned in the previous sections.

Attitude Polarization. A consequence of the above behaviours, particularly that of biased assimilation, is the widening of attitudes among members (e.g. Lord, Ross \& Lepper, 1979), However, attitude polarization findings are not without their criticisms. Miller and colleagues (1993) argued that only measures that ask participants if their attitude has changed show an effect whereas those measured with a pre-post design will not. In their study, they conducted four conceptual replications of Lord and colleagues' (1979) work (two on capital punishment and two on affirmative action). While they consistently replicated the biased assimilation effect and perceived attitude change, no polarization effects for a pre-post design were found. Another issue may stem from the ambiguity surrounding the construct of attitude, for both researchers and participants alike (Pomerantz, Chaiken, \& Tordesillas, 1995). Pomerantz and colleagues (1995) also argue that knowledge, personal importance, ego-involvement, extremity and certainty can also play a part in attitude polarization, with higher levels of the above factors leading to greater polarization. They go on to show that these factors load on to two separate dimensions; embeddedness which includes knowledge, personal importance and egoinvolvement and commitment which involved attitude extremity and certainty, with only the latter significantly affecting attitude polarization. However, this work is at odds with 
work by Taber and Lodge (2006) who argue for a 'sophistication effect,' such that more knowledgeable people will show greater polarization because they are better able to counter argue incongruent information.

Individual Differences and the Confirmation Bias. Despite extensive work examining both the mechanisms and behaviours surrounding the confirmation bias, little work has been done examining individual differences (Rassin, 2008), prompting Rassin to create his own personality measure to specifically examine differences, however this research is mainly descriptive with little theoretical insight. Other variables have looked at the behaviours discussed above that relate to the confirmation bias. One variable that has been looked at with respect to selective exposure is 'closed-mindedness' using Rokeach's (1960) dogmatism scale, Byrne's (1964) Repression-Sensitization Scale or the Right Wing Authoritarianism scale (Altemeyer, 1996; as cited by Hart, el al., 2009). Indeed, Hart et al. (2009) show that selective exposure is higher for individuals scoring high on closed-mindedness scales than those scoring low on these scales.

Another variable that plays a role is self-esteem. The need for self-esteem strongly influences an individual's cognition and behaviour (Allport, 1961; Pyszcynski, Greenberg, Solomon, Arndt, \& Schimel, 2004) and has been shown to be an important mediator of biased behaviour (Pyszcynski \& Greenberg, 1987; Tesser, 2000 ). The selfserving attribution bias can be seen as a type of confirmation bias, with individuals attributing their successes to themselves but attributing external factors as responsible for their failures (Miller \& Ross, 1975; Pyszcynski \& Greenberg, 1987; Blain \& Crocker, 1993). Research has also shown that variations in self-esteem can affect how individuals 
react to information with individuals with high self-esteem better able to rationalize threatening information, presumably because individuals with high self-esteem draw upon a larger pool of positive experiences and, as such, are less likely to be threatened by the information (Nail, Misak, \& Davis, 2004; Steele, Spencer,\& Lynch, 1993). Indeed, the self-affirmation literature supports this idea (Cohen, Aronson, \& Steele, 2000).

Lastly, although the confirmation biasis not associated with intelligence and cognitive ability (Stanovich \& West, 2008), individuals with greater cognitive ability have a greater 'bias blind spot', in that the more intelligent an individual, the more likely they were to attribute a confirmation bias to others as opposed to themselves (West, Meserve, \& Stanovich, 2012). The researchers argue that this difference may be due to intelligent people expecting to outperform others on cognitive tasks and the idea that they hold their cognitive ability as an important aspect of themselves.

The Confirmation Bias and Uncertainty. A necessary requirement for the confirmation bias is uncertainty and the major cause of this uncertainty is conflicting information. By definition, individuals will be unable to show bias in assimilating, selectively recall or selectively expose themselves to information when all the information is congruent. Current models of the confirmation bias suggest that uncertain information is motivating, and as such individuals have a need to gather information and reduce the uncertainty (Trope \& Liberman, 1996). For example one study had participants evaluate the performance of two boys. Participants were told that they were either from a high or low socioeconomic status background to manipulate consistent or inconsistent information. Participants who were given inconsistent information paid 
more attention to the boy and gave more complex evaluations (Hilton, Klein, \& von Hippel, 1991). Additionally, Trope and Ben-Yair (1982) showed that if participants were given 'uncertain' feedback following their 'initial task' that measured their mental abilities, they were more motivated to work on that task than on a task in which they were given more certain and diagnostic feedback. However, Sorrentino and colleagues (Sorrentino \& Roney, 2000; Sorrentino et al., 1988; Hodson \& Sorrentino, 1997) have proposed that uncertainty is not motivating for everyone. Rather, individuals differ drastically in how they approach and react to uncertainty.

\section{Uncertainty Orientation}

"Uncertainty is a fact with which all forms of life must be prepared to contend. At all levels of biological complexity there is uncertainty about the significance of signs or stimuli and about the possible consequences of actions" (Kahneman \& Tversky, 1982, p. 144).

Although uncertainty plays a pervasive role in our lives, uncertainty reduction has been theorized as an innate biological requirement (Kalma, 1986; Inglis, 2000). Indeed individuals have a need to understand, predict and control their environment (Bandura, 1997). However, the theory of uncertainty orientation (Sorrentino \& Roney, 2000; Sorrentino, Short, \& Raynor, 1984) suggests that this may not be true for all people. Although individualshave an innate tendency to reduce uncertainty, the theory of uncertainty orientation positsdifferent ways in which individuals react to and handleuncertainty. It distinguishes between people who are uncertainty-oriented (UOs) and those who are certainty-oriented (COs). Those who are oriented towards uncertainty 
actively try to understand the causes of their uncertainty and confront uncertainty with the intention of resolving it, whereas those who are oriented toward certainty attempt to maintain certainty, gravitating towards predictable environments and preferring nondiagnostic information to diagnostic information (Sorrentino \& Roney, 2000; Sorrentino, Short \& Raynor, 1984; Sorrentino et al., 1988). Whereas, COs maintain what is already known about the self and their environment, UOs explore the potential implications of uncertainty. However, UOs only engage in active, systematic information processing and decrease their passive, heuristic information processing when they encounter uncertain situations that are important and self-relevant. In situations that have little importance, UOs are not motivated to seek out new information and thus engage in passive information processing. COs exhibit the opposite pattern. In situations that are not personally relevant and devoid of uncertainty, COs will engage in greater information processing than in uncertain situations because rather than being motivated by uncertainty like UOs; COs gravitate and are motivated by certain and predictable environments. This pattern reverses for non-personally relevant situations whereby UOs will use more heuristic processing and COs will use less. (Sorrentino \& Roney, 2000; Sorrentino et al., 1988). Sorrentino and Short (1986) summarize uncertainty orientation as, "a cognitive individual difference variable related to information value. It serves as a situational screening device that, when identifying relevant situations, arouses the appropriate source of motivation" (p.393).

It should be noted that although the theory of uncertainty orientation is similar to Rokeach's (1960) theory that suggests open and closed-mindedness as a stable intelligence-related dimension, uncertainty orientation suggests that there are situations 
when UOs may appear smarter and/or perform better on a specific task than COs, however there are situations in which COs will outperform UOs. As mentioned, UOs will be more motivated in uncertain situations involving uncertainty, whereas COs will be more motivated in situations that are more predictable. Thus, it is the match between the person's orientation and the specific situation that will determine how individuals process information and behave

Uncertainty orientation, like the confirmation bias, reflects an interplay between cognition and motivation, that is situated in uncertainty and as such is suggested to be an important individual difference variable.

Uncertainty Orientation and Information Processing. Although incongruent information may be very effective in learning something new, it also creates a sense of uncertainty where individuals must engage in effortful processing to make sense of the world. However, COs prefer to maintain what they already know and tend to avoid inconsistent information and cognitively processing it (Shuper \& Sorrentino, 2004; Hodson \& Sorrentino, 2001). One study by Roney and Sorrentino (1987) showed that COs have much more rigid, distinct, black and white categories. While this may be advantageous in terms of cognitive efficiency, it may be difficult for COs to reconcile views between overlapping categories. In another study, Sorrentino et al. (1988, study 1), participants were told that the University was considering comprehensive exams. Participants were told that the University was planning on implementing these exams either in 1-2 years or 5-10 years in order to manipulate personal relevance and then were given either one-sided or two-sided arguments for the plan. The research showed that UOs, consistent with previous research (Petty and Caciopo, 1981; Lumsdaine and Janis, 
1953), exhibited greater persuasion when presented with a two-sided message than when presented with a one-sided message under a high personal relevance condition.

Ostensibly, UOs faced with the uncertainty expended cognitive effort in order to resolve the inconsistency and in doing so were more persuaded by the incongruent two-sided message. However, COs behaved oppositely and were less persuaded by the two-sided message than the one-sided message under high personal relevance.

Furthermore, Sorrentino and colleagues (1988, study 2) found differences between COs and UOs in the effect of personal relevance and argument type on attitude change. The researchers here demonstrated that UOs showed greater attitude change when personal relevance was high and when argument strength was strong. This was expected, as one tends to focus more on arguments that are personally relevant. However, the opposite occurred for COs; the degree of persuasion actually decreased for arguments with high personal relevance compared to low personal relevance. Similarly, Sorrentino et. al., (1988, study 2) found that when reading expert versus non-expert advice, COs reacted opposite to UOs. COs had the greatest difference between high and low expert conditions when the issue was highly relevant, indicating that they were affected by the heuristic of an'expert' and not the message itself, whereas UOs were only affected by the source in low personally relevant situations. The first experiment demonstrates that since certainty and predictability are preferred by COs, they don't scrutinize arguments that prove inconsistent, but rather use heuristics in an attempt to maintain certainty. The second experiment seemingly showed that under high personal relevance COs are not motivated to think for themselves and tend to focus on heuristics, in this case, expert advice. UOs on the other hand, were more motivated by the personal 
relevance and focused more on the strength of argument. It is important to not, that when the issue was not personally relevant, COs do seem to think for themselves, demonstrated by COs focusing more on strength of the argument when personal relevance was low.

A study by Driscoll, Hamilton and Sorrentino (1991) showed that UOs are more likely to attend to information that is not congruent with one's world view, whereas COs were more likely to attend to congruent information, indicating a difference in cognitive processing. In a study by Hodson and Sorrentino (2001), participants were given Tajfel matrices (see Tajfel et., al. 1971) to assess in-group bias. It was found that under conditions of uncertainty, COs showed much more in-group bias, whereas there was no difference between conditions for UOs. The effect was presumably due to the understanding that in conditions of uncertainty, COs focus on heuristics, in this case, "to look after one's own." Moreover, a study by Shuper and Sorrentino (2004) showed that UOs scrutinize messages when there is an imbalance between the message and the source (e.g. minority/majority), whereas COs were more likely to scrutinize the message when there was consistency between the source and the message, demonstrating differences in systematic processing between UOs and COs in consistent and inconsistent situations. It is important to note, then, that the differences in uncertainty orientation are not due to differences in cognitive ability or capacity, but rather a function of one's motivational inclination towards uncertainty. Taken together these four studies show that COs decrease use of systematic processing when faced with uncertainty/inconsistency, especially under high personal relevance, whereas UOs increase their cognitive processing under these conditions (Sorrentino et al., 1988; Hodson \& Sorrentino, 2001). Furthermore, UOs are more likely to attend and scrutinize incongruent information than 
are COs (Driscoll et al., 1991; Hodson \& Sorrentino, 2003).

\section{Embodied Cognition}

The past three decades have seen the advancement of embodiment research in social psychology. This phenomenon suggests that social information processing does not just create bodily states and behaviour, but rather involves and is influenced by them. Indeed this view is compatible with many of social psychology's core assumptions, namely that our thoughts, feelings, and behaviours are influenced by others and situations.

Disembodied views of cognition suggest that knowledge is exclusively part of the semantic memory system and does not involve perception, action or affect. However, although a complete conception of embodied cognition is not well defined (Gibbs, 2006; Neidenthal, Krauth-Gruber \& Ric, 2004; Wilson, 2002; Smith \& Semin, 2004; Barsalou, 2008a) it is agreed that bodily states, at least in some way, underlie cognition.

Embodied theories depart from traditional theories of knowledge in that conventional theories suggest that knowledge is based on mental representations that reprocess sensory, motor or even introspective experiences (Barsalou, 1999). For example, when a person sees a puppy, one has a sensory experience. They will have a visual experience from seeing it, a tactile experience from petting it, and an auditory experience and olfactory experience from hearing and smelling it. They will also have a motor experience from moving their hands along its head and back and have an introspective experience, perhaps happiness or fear. The conventional view would suggest a symbolic system converts these states producing a description of the event in a 
separate system of amodal (referring to the absence of a specific modal area of processing e.g. the sensorimotor system) in preference of a conceptual schematic network. An embodied view hypothesizes that these initial experiences can be mappedthrough a representation of language but remain situated in the body. Furthermore, the conventional cognitive view suggests that processing of an event or word, does not involve processing through the sensory or motor areas of the brain but rather through recall within this symbolic memory system. The embodied view, however, suggests that instead of recalling an experience involving the activation of amodal representations, recall involves the original sensory, motor or introspective areas. Rather than simply recalling your dog experience through this amodal system, you will also recall it through the appropriate sensorimotor areas. In other words, when one reads a book, it does not simply create a symbolic representation, it induces a simulation of the experience.Although a lot of the research that will be explored in this paper suggests the need of actual bodily states, this is not required. A simulation of the bodily state in the motor area may be enough. As research has demonstrated (Baraslou, 1999; Wells \& Petty, 1980; Duclos et al., 1989), embodiment may range from simulation to full execution.

In 1980, Wells and Petty showed that nodding one's head up and down in agreement while listening to a persuasive message resulted in a greater positive attitude to the message than individuals who shook their head left and right in disagreement. Strack, Martin, and Stepper (1988) showed that those who were told to smile found cartoons significantly funnier than those who had their smiles inhibited (by gripping a pen in their mouth). A study by Duclos et al. (1989) found that people who took angry, 
fearful, or sad body positions would experience an increase in those moods respectively. Furthermore, a study by Cacioppo, Priester and Berntston (1993) showed that Chinese symbols were rated more positively during arm flexion than during arm extension, presumably because arm flexion is related to approach, whereas arm extension is related to avoidance.

The above studies represent what is known as online embodiment; that bodily responses facilitate cognitive processing (Wilson, 2002; Neidenthal, Baraslou, Ric, \& Krauth-Gruber, 2005). This process is differentiated from offline embodied cognition; the idea that embodied simulations will occur in conjunction with semantic mental representations. ,. In other words, just by thinking about an object can produce an embodied state. In one study by Chen and Bargh, (1999), participants were given positively and negatively valenced words such as love or hate. Participants were then asked to either pull a lever toward themselves or push it away when a word was presented. Participants responded more quickly when the behaviour and the valence matched (pulling and positive or pushing and negative). Similarly, a study by Bargh, Chen and Burrows (1996) showed that when participants were given words that fit to an elderly stereotype, for example 'grey' or 'Florida', they took longer to walk down the hall to the elevator than did control participants. These studies demonstrate that a physical response can be engaged when individuals process information offline. Some embodiment researchers cite this as evidence that suggests that just thinking about something involves activity in motor areas (Niedenthal, Krauth-Gruber, \& Ric, 2004; Glenberg \& Kaschak, 2002; Lakoff \& Johnson, 1999). Neidenthal and colleagues (2004) argued that the mirror neuron system, which corresponds to both observed and performed 
behaviours could be, at least in part, responsible for embodied cognition. However, there is still disagreement on exactly how mirror neurons function (Gallese, Kevsers, Rizzolati, 2004) and how they would function in relation to embodied cognition is still not understood.

Neuroscience research has substantiated these ideas as well. Work by Damasio, Tranel and Damasio (1993) has shown that priming verbs activate the same areas associated with motor movements, whereas priming colours activate the visual processing cortex. Similarly, work has shown that being primed with manipulable objects, for example, a hammer, activated the same neural areas associated with grasping (Chao \& Martin, 2000).

These above findings, among others, have helped build on the idea that the mind is fundamentally embodied. The embodiment hypothesis suggests that cognition is intertwined in the body's interactions with the world (Wilson, 2002) and as such not only influences but may also involve our perceptions and actions. Thelen, Schoner, Scheir, \& Smith (2001) wrote in regards to embodied cognition:

"To say that cognition is embodied means that it arises from bodily interactions with the world. From this point of view, cognition depends on the kinds of experiences that come from having a body with particular perceptual and motor capacities that are inseparably linked and that together form the matrix within which memory, emotion, language, and all other aspects of life are meshed. The contemporary notion of embodied cognition stands in contrast to the prevailing cognitivist stance which sees 
the mind as a device to manipulate symbols and is thus concerned with the formal rules and processes by which the symbols appropriately represent the world (p. 5)."

According to Thelen and colleagues (2001) then, our bodies and environment do not simply interact with cognition, they play a necessary role in shaping and developing our cognitive capacities.

\section{Embodiment and Conceptual Metaphor.}

"When we describe the workings of emotion, ideas, or trends of character, we almost invariably use terms that also denote properties and processes observable in the world of nature. Terms such as warm, hard, straight refer to properties of things and of persons. We say that a man thinks straight; that he faces a hard decision; that his feelings have cooled. We call persons deep and shallow, bright and full, colorful and colorless, rigid and elastic. Indeed, for the description of persons we draw upon the entire range of sensory modalities ... the language of social experience and action reveals the same characteristic. We are joined to people with ties and bonds; classes are high and low; groups exert pressure, maintain distance from other groups, and possess atmosphere.” (Asch, 1958, p. 86 -

It has been suggested that language itself is grounded in human action (Glenberg, 1997; Glenberg \& Kaschak, 2002; Newton, 1996; Johnson \& Lakoff, 2002). In this view, the meaning of the word corresponds to the action. For example, the description, 
"it has a handle on the top" affects how we are prepared to deal with it. In a study by Glenberg and Kaschak, (2002), participants were given sentences like "open the drawer" or "open the plate." The researchers assumed that one has to pull an object towards oneself in order to open it (i.e. open a drawer) and as such could not open a plate. They were also given a response box with 3 buttons in a column (far, close, and middle). The experimenters asked participants if the sentences made sense. Participants had to begin with their hand on the middle button and then move to the correct answer when shown the word. Participants were faster answering when the yes button was the far button (i.e. Yes-far, No-close) when given sentences like "open the plate" but were faster when yes was the close button (i.e. Yes-close, No-far) for sentences like "open the drawer" ostensibly because in order to understand the sentence one first had to mentally embody that action by pulling the plate/drawer inwards to 'open it.'

Furthermore, current research has supported the idea that since language is embodied then our bodily states are also intertwined with abstract thoughts and metaphor (Lakoff \& Johnson, 1980; Landau, Meier, \& Keefe, 2010). For example, the use of cleanliness to refer to morality is evident through everyday common language "feeling dirty," "wiping your hands clean" or "clean slate." A series of studies have shown that our sense of morality is grounded in a physical sense of cleanliness (Zhong \& Liljenquist, 2006; Lee \& Schwarz, 2010). In these studies, it has been shown that postdecisional dissonance of moral transgressions can be appeased by the act of cleaning and that those who do commit wrongdoings find cleaning products (either mouthwash, if done orally or hand sanitizer, if done by writing) more alluring. Furthermore, those who have cleaned themselves feel more self-righteous and are more likely to make harsher 
judgments of wrong behaviour.

Cleanliness has been shown to go beyond morality. A study by $\mathrm{Xu}$, Zwick, and Schwarz (2011) showed that by cleaning oneself, a participant's perception of the influence of badluck could be 'washed away.' Furthermore, Lee and Schwarz (2010b) showed that the act of washing one's hands can reduce other post-decisional dissonance effects. In their study, participants were asked to pick between Musical Compact Discs (CDs) or jams. Those participants who examined a soap bottle exhibited the typical effect of justifying their choice, either by rating the CD as better or the jam as better tasting. Those whoactually washed their hands did not exhibit this effect. Thus the expression 'a clean slate' appears to be not only not an expression, it extends into cognition as well.

The past decade has seen an explosion of research examining the ways in which metaphor can be used to shape cognition. Vertical position has been related to perceptions of power as well as attractiveness (Schubert, 2005; Meier \& Dionne, 2009), increased spatial distance was shown to decrease emotional attachment (Williams \& Bargh, 2008b) and physical warmth has led to increased feeling of perceived friendliness and emotional attachment (Williams \& Bargh, 2008a; Ijzerman \& Semin, 2009), to list just a few examples.

Weight, as a metaphor, has importance in many languages including English, Dutch, Spanish and Chinese (Jostmann, Lakens\&Schubert, 2009). People 'weigh their decisions' they 'weigh their options' and importance 'carries weight.' In a study by Jostmann, Lakens and Schubert (2009), the investigators show that the relationship 
between weight and importance is not only linguistic and metaphorical but also important for cognition. They found that those holding a heavier clipboard increased the importance of fair decision-making procedures. In addition, it caused more elaborate thinking, which was evident by a higher consistency between related judgments. Furthermore there was an increase in the polarization of the participants' ratings for strong versus weak arguments.

In another study by Lee and Schwarz (June $2^{\text {nd }}, 2011$ personal communication; Lee \& Schwarz, 2012) the expression 'on one hand and on the other', describing a balance of evidence, was coupled with the embodiment of moving hands, palms up alternatively up and down. When participants were asked to move their hands in this way, they showed an increase in the importance to 'balance in life', an increase in balance of work and leisure when making schedules and more balance of price and quality in a production task.

Embodiment Mechanisms. The processes behind embodiment are not well established. Despite all the evidence, no major theory has emerged to explain it (Smith \& Semin, 2004; Neidenthal et al., 2005), although a few hypotheses have been ventured (Barsalou, 1999; Neidenthal et al., 2005; Glenberg \& Kaschak, 2002). As discussed, the primary view is that cognitive representations are situated in the brain's sensorimotor system and through our experience in the world we develop mental representations of these abstract concepts that can then be activated to influence our thoughts (Neidenthal et. al, 2005; Barsalou, 2008b). In this model, cognition works similarly to current models of amodal and symbolic mental representation which is the basis for most models of semantic priming and goal priming. However, because behaviouris based in the 
perceptual and sensorimotor system, associations can be activated by stimulating those specific areas and not only by activating symbolic connections.

Metaphor has a strong link to linguistics and, because of the link between cognition and linguistics, metaphor has been conceptualized as a way to understand abstract concepts using more concrete concepts (Gibbs, 2006). Although these concepts may be superficially dissimilar (e.g. warmth and friendliness), they influence our cognition and shape our thoughts and behaviour. Although some have argued whether metaphors are simply a linguistic tool, the research reviewed above provides empirical evidence that metaphors influence processing in ways that would not be predicted from a schematic model (Landau, Meier, \& Keefer, 2010). However, it should be noted that this metaphor perspective does not replace the schematic perspective;indeed, dealing with social concepts, people use schematic information. Rather, the metaphor perspective enriches this view by suggesting that people, in addition, access bodily representations, and provides an avenue for exploring other empirical findings that would not be possible without this perspective.

Understanding the effects of embodied metaphor requires drawing a distinction between the effects of conceptual metaphor and embodied cognition. Recall the puppy example, whereby our concept of the puppy is shaped by sensorimotor and proprioceptive representations. In the same way, our understanding of a mouse or of a bowling ball or any other object includes specific representations. These representations are directly tied to our understanding of the object. While many objects may be smooth, the specific 'smooth' representation of a bowling ball or of a mouse is inherently linked to that object and derived from previous experiences with that category. Work that 
examines the effect of an embodied representation, such as smiling or nodding (e.g. Strack, Martin \& Stepper, 1988; Wells \& Petty, 1980) would be examples of this. Another example comes from work by Neidenthal, Wiekileman, Mondillon and Vermulean (2009) who showed that when people had to make judgments about whether they enjoyed or were disgusted by certain concepts (viewed as words, e.g. sun, cuddle, or murder) they also exhibited activity association with their facial muscles (e.g. the zygomaticus major muscle associated with smiling). This suggests that these muscles are activated in association with specific stimuli, but do not provide evidence for the link between metaphor and behaviour (Landau, Keefer, \& Meier, 2010)

On the other hand, conceptual metaphor theory postulates that representations do not have to be directly linked to their concept. Consider the work by Williams and Bargh (2008a) who showed that people's perceptions of friendliness and emotional closeness of another individual are increased when holding a warm cup. Indeed, while we may have learned early in our life about the association of warmth and closeness while being cradled in our mother's arm, we can think about the temperature outside and what we should wear, without any metaphorical linking. However, this distinction is not meant to suggest that the processes are mutually exclusive. Rather, it is suggested that through scaffolding on early experiences, we develop the basis for these conceptual metaphors.

Work examining embodied metaphor from a social neuroscience perspective has also provided evidence of the link between metaphor, cognition and behaviour. One study showed that the regions that are associated with physical warmth were also activated in violations to a trust game (Kang, Williams, Clark, \& Bargh, 2010). 
Individual Differences. Current conceptualizations of embodied cognition argue that embodiment manipulations work similar to priming of goals. Recent priming research has suggested that priming may induce goal activation (Forster, Liberman, \& Friedman, 2007), and that these goal states can interact with one's motivation (Cesario, Plaks, \& Higgins, 2006; Hart \& Albarracin, 2009). For example, Cesario and colleagues (2006) found, when replicating the Bargh (1996) elderly stereotype prime (experiment 2), participants with positive attitudes towards elderly individuals walked more slowly, whereas those with negative attitudes walked more quickly. Similarly, Harts \& Albarracin (2009), showed that priming achievement only facilitated motivation to achieve a goal with individuals with high achievement motivation, whereas it inhibited the goal in individuals with low achievement motivation. Similarly, priming achievement in those with low achievement motivation instilled goals of fun and leisure, whereas it inhibited these goal in those with high achievement. Dijksterhuis and Aarts (2010) have argued that rather than motivation being a conscious mental representation to achieve some volitional behaviour, which has traditionally assumed to be the case, recent research (e.g. Soon, Brass, Heinz, \& Haynes, 2008; Bargh et al., 2001; Aarts et al., 2008) suggests that people are only consciously aware of their motivation after they have unconsciously had it activated.

In addition, work from Sherman and Clore (2009) showed that processing speed was facilitated when immorality words (e.g. cheat or hate) were paired with black and morality words (e.g. helping or honesty) were paired with white. However, faster associations were found among participants who had higher desirability for cleaning products and among those who had been primed with immorality, suggesting that one's 
motivation of cleanliness moderated the priming task. Work from the embodiment literature has also contributed to this idea. For example, depressed individuals typically prefer areas that are lower with respect to vertical space (Meier \& Robinson, 2006), or those who have a stronger power motive are quicker to react to primes with higher spatial locations (Moeller, Robinsons, Ode,\& Zabelina, 2008). The study by Moeller and colleagues, (2008) showed that individuals who had a need for power and dominance were quicker at responding to a cue at the top of a screen than at the bottom of the screen, than those that did not have as strong a motivation for dominance. The researchers argued that one's motivation for power carried over into the vertical sensory domain, which has been demonstrated to correlate with power. In addition, work by Schubert and colleagues has shown that making a fist leads male, but not female participants to see themselves as more assertive (Schubert \& Koole, 2009; Schubert, 2004).

Despite the extensive research into embodiment over the past decade, only a few studies have examined individual differences (Meier, Schnall, Schwaz, Bargh, in press). Although personality theorists have long contended that an individual's thoughts and behaviours will predictably vary, little research has integrated individual differences in embodiment theory. The motivational and cognitive overlap between the confirmation bias and uncertainty orientation allows for exploration on individual differences and embodied cognition

\section{The Present Study}

Uncertainty orientation, like the confirmation bias, is an interplay of motivation, cognition, and uncertainty. As such, it appears to be a potential moderator of the confirmation bias. As discussed, uncertainty orientation theory suggests that people will 
differ in the degree in which they are actively engaged by uncertainty. Thus UOs and COs should differ in how they react to new information and how much they orient to what they believe or already know. With respect to the confirmation bias, UOs should be more willing to confront uncertainty in search for 'truth,' be actively engaged by uncertain situations and engage in more systematic processing in these situations. In this way, UOs should be guided by accuracy goals as depicted by theories of motivated hypothesis testing (Kunda, 1990; Trope \& Liberman, 1996). Therefore UOs should be less likely to seek out only congruent information and less biased assimilation. Previous research has shown that UOs are more likely to seek out threatening and efficacious information (Brouwers \& Sorrentino, 1993) and engage in more systematic processing when confronting incongruent arguments (Sorrentino et al., 1988; Shuper \& Sorrentino, 2004). COs, on the other hand, will be more likely to seek out certain and predictable situations and will be less engaged by uncertain situations, typically circumventing uncertainty, either by choosing environments that limit uncertainty (Sorrentino \& Hewitt, 1984; Sorrentino et al., 1992) or by using heuristics (Sorrentino et al, 1988). As such, they should be guided by directional goals, seeking congruent information and be biased in processing information.

In addition to the effect of uncertainty orientation on the confirmation bias, this study will be exploring the embodied metaphor of 'weighing both sides' to create balance. While one might expect embodying this concept to produce a more balanced search and processing for all individuals, recent theorizing into embodied metaphor suggests that metaphors highlight one's inherent motivation.

Although it is expected that UOs will be more likely than COs to seek out and 
interpret incongruent information in a balanced way, an interaction should be seen whereby the embodiment manipulation should intensify UOs need to confront and resolve uncertainty, resulting in less biased information search and assimilation of the information. Conversely, because COs do not have this need to resolve uncertainty, they should not be affected by the manipulation and as such not differ from the control group. Under this view, embodying this motion activates the physical concept of balance, which in turn activates associations related to the metaphorical concept of balance, resulting in less biased information processing. However, UOs who have the concept of balance more accessible in personally relevant situations should be affected by this manipulation more than COs.

However, an alternative hypothesis is theorized in which the embodiment manipulation of balance metaphorically represents attributing weight to arguments. Work from Cesario, Plaks and Higgins, (2006) and Hart and Albarracin (2009) suggests an interplay between inherent motivations and primes. Other work from Moeller, Robinson and Zabelina, (2008) showed that those low in power motivation were actually slower in responses to cues at the top of the screen than to the control cues at the left and right position, suggesting that those with low motivation for power exhibited the reverse effects. Similarly, although making a fist activates the concept of power for both men and woman, it increases the want for power for men but decreases it for women (Schubert, 2004). Thus, if providing weight increases personal relevance, this may in turn strengthen UOs need to resolve the uncertainty, but alternatively strengthen COs need to maintain certainty, thus resulting in greater bias for COs. Thus, COs should may become even more unbalanced in the same way that those who disliked elderly people walked 
faster.

In addition to these hypotheses, exploratory research will also examine the effects of uncertainty orientation and embodied cognition on selective recall and attitude polarization. These dependent variables were studied as they often are examined in conjunction with the biasing effect of attitudes on information processing. More importantly, embodiment effects relating to attitude polarization and selective recall will demonstrate that embodiment affects encoding of information. Interactions regarding embodiment and uncertainty orientation with respect to attitude polarization suggest that participants are incorporating the information they read differently across conditions. If participants exhibit less polarization, or a decrease in attitude strength, it would provide evidence that participants are not simply seeking information and rating arguments in a more balanced manner but internalizing the information. As such UOs may tend to depolarize more while in the embodiment condition, with COs either hyperpolarizing or showing no effect. Additionally, if embodying balance increases systematic processing for UOs, UOs should then be more likely to elaborate and subsequently be more likely to recall information. Similarly, if it increases heuristic style processing for COs; this should be reflected in less elaboration and worse memory for COs. The general hypothesis of the present study, therefore, is that UOs will show more evidence of balanced reasoning in the embodiment condition than COs, and this difference will be greater than in the control condition. 
METHOD 


\section{Overview}

A general linear model design examining the interacting effects of embodiment and uncertainty orientation, resulting in a 2 (embodiment: hands 'up' versus hands down) x 2 (uncertainty-orientation: COs and UOs) was analyzed on the five dependent variables, namely selective exposure, biased assimilation, selective recall, attitude polarization, and the disconfirmation bias.

\section{Participants}

A total of 180 introductory psychology students from the University of Western Ontario were recruited through the Psychology participant pool. Data from 6 participants were lost due to computer failure. This resulted in a total of 174 participants (124 female and 50 male) aged 16 to $35, M=18.68,(S D=2.03)$. Participants received 1.5 credits towards their introductory psychology class (Psychology 1000) for their participation in the study.

\section{Independent Variables}

Uncertainty Orientation. In line with Atkinson's work (Atkinson, 1964;

Atkinson \& Feather, 1966) that argues for both the approach and the avoidant measures of a personality dimension, uncertainty orientation is assessed by one's desire to resolve uncertainty and one's desire to maintain predictability (see Frederick and Sorrentino, 1977 and Sorrentino et al., 1990 for reviews). It is assumed that one's desire to maintain clarity is independent from one's motivation to resolve uncertainty. As such, an individual may be high or low on both of these motives and thus a resultant measure, one that controls for both, is a better predictor than a single measure. Therefore, uncertainty 
orientation is the resultant measure of uncertainty, composed of individual measures of $n$ Uncertainty (uncertainty scores standardized) and $n$ Authoritarianism (authoritarianism scores standardized).

Uncertainty is measured by a projective measure based on the Thematic Apperception Test (TAT; Sorrentino, Hanna,\& Roney, 1992) and is used to assess an individual's desire to resolve uncertainty about the self and the environment. The TAT included 4 lead-in sentences such as "Two people are working in a laboratory on a piece of equipment" and then asked participants four questions to help lead their stories (See Appendix A). An expert scorer, who has achieved an inter-rater reliability of greater than 0.90 on pre-approved materials, scored the TAT.

The authoritarian component is measured using Cherry and Byrne's (1977) acquiescence-free message of authoritarianism, which measures authoritarianism using a 21-item measure on a 6-point scale, known as the F-scale (Appendix B). For example, one question asks "What the youth needs most is strict discipline, rugged determination, and the will to work and fight for family and country."

Each participant's Uncertainty and authoritarian scores are standardized into zscores and subsequently the authoritarian z-scores are subtracted from the Uncertainty zscores to give the resultant measure of uncertainty orientation (RUM) with those receiving higher scores considered to be more Uncertainty-Oriented and those receiving lower scores considered to be more Certainty-Oriented.

Embodiment. Since adding physical weight actually 'gives weight' to an idea or an object in that it makes it more important (Jostmann, Lakens, \& Schubert, 2009; 
Schneider, Rutjens, Jostmann, \& Lakens, 2011), giving weight to two objects or ideas should make both ideas important, leading to a more balanced approach. Adapted from Lee and Schwarz (2012), the balancing gesture that often accompanies weighing ideas or the expression 'on the one hand and on the other' was used as an embodiment manipulation to activate this metaphorical notion of balance. This gesture has three features. The first is that palms are open and facing upwards, the second is that arms move alternately up and down and the third is that hands are out to the side of the body. Because palms are faced upwards, this condition will be referred to as the 'up' condition. A control condition was also used, in this case with both palms facing down, and to the side, moving up and down ${ }^{2}$. Likewise, this condition will be referred to as the 'down' condition.

Attitudes. Participants were able to choose between one of four important issues; abortion, capital punishment, employment equity, and same-sex marriage. Specifically participants were asked "which of the following issues is most important to you." Following this, participants were asked whether they were in favour of the issue they chose or opposed (abortion was listed as prochoice or prolife). In line with Taber and Lodge (2006), participants were then asked about their attitudes on a single attitudinal measure (measured from $1-100$, with $1=$ indifferent and $100=$ extremely strong) and their perceived knowledge on the issue (measure $1-5$, with 5 being very knowledgeable, and 1 being not knowledgeable).

\footnotetext{
${ }^{2}$ Previous research using this manipulation also used a second control condition in which participants hands were held palm up, but did not move. The researchers found no differences between both this condition and the 'down' condition (Lee \& Schwarz, Personal Communication, June $2^{\text {nd }}, 2011$ )
} 
DemographicsQuestionnaire. Participants were given a series of demographic questions that pertained to their age, sex, and ethnicity (See Appendix C).

\section{Dependent Variables}

The dependent variables were assessed in conjunction with an information board derived from work conducted by Taber and Lodge (2006). The information board consisted of 16 cells, in a 4 x 4 matrix (See Appendix D). Each of the cells were blank but participants could click on them to reveal an argument. Arguments were taken from various online political groups and from Taber and Lodge (2006). Furthermore, each row was labeled with the name of a political group (e.g. Canadians In Favour of SameSex Marriage) so that participants would know which arguments would be congruent with their attitudes and which arguments would be incongruent with their attitudes (for a list of arguments please see appendix E). The names of each group explicitly stated their position on the issue. Participants were instructed to click on 8 of the 16 cells (Appendix F). Before clicking on a cell participants were asked to mimic the embodiment for ten seconds (Appendix G) When participants clicked on a cell it brought them to a separate screen which stated an argument (Appendix H) and then participants were allowed to rate the argument from 1-100 using a sliding scale (Appendix I). Following it would bring them back to the matrix (Appendix J)

Selective Exposure. Selective exposure was measured by how many congruent arguments participants chose from the matrix, with a maximum of 8 and a minimum of 0 . Thus selective exposure is indicated by higher amounts of congruent versus incongruent searching. 
Biased Assimilation. Biased assimilation was measured by the average ratings participants gave to congruent arguments (e.g. arguments in favour of the issue, when the participants were in favour of the issue or arguments against the issue when participants were against the issue) versus the average ratings of incongruent arguments. Participant position will be used to denote whether participants are in favour or against the issue (e.g. in favour of capital punishment), whereas argument direction will denote whether the argument was in favour or against the issue. Larger differences between congruent and incongruent ratings are indicative of biased assimilation. It should also be noted that analyses are collapsed across topics and pro-choice was grouped with'against' and prolife grouped with the 'in favour' arguments.

Disconfirmation Bias. Unbeknownst to participants, the time it took for participants to read each argument was measured. The disconfirmation bias was measured as a function of average time taken to read congruent arguments versus average time of incongruent arguments. Longer times indicate that people are spending more time and more cognitive resources trying to mentally counter argue the incongruent arguments. Time was recorded until participants indicated their rating of the argument.

Selective Recall. Participants were given a surprise recall task and asked to recall as many of the arguments as they could. Two coders independently coded responses for congruent $(\alpha=.95)$ and incongruent arguments $(\alpha=.94)$. Participants also occasionally wrote comments and additional arguments not listed. Coders independently coded these arguments $(\alpha=.86)$. Coders subsequently met to discuss the discrepancies. Average recall frequency was calculated by taking the number of arguments recalled and dividing it by the number of arguments viewed for each position (e.g. individuals who selected 5 
arguments in favour of the issue but recalled 2 of them would be given a score of 0.4). Selective recall is measured by a difference in congruent arguments recalled versus incongruent arguments recalled.

Attitude polarization. Participants' attitudes measured at the beginning of the information matrix were subtracted from time their attitudes at the end of the matrix task. Positive values indicate attitude polarization.

\section{Procedure}

Participants were greeted by an experimenter and then were asked to read the letter of information and sign the consent form. All participants were tested individually in a closed room with a single computer. After signing the consent form participants began the experiment. The first task was the sentence completion task and authoritarianism measure used to identify a participant's uncertainty orientation, followed by the demographic questionnaire.

Following this first task participants were told that the second part of the experiment was meant to examine multi-tasking and decision making. Participants were told that they would be mimicking a motion while reading some material and answering questions. Participants were randomly assigned to the 'up' or 'down' embodiment condition. An experimenter would then model the motion and ask participants to mimic it. Special care was taken to make sure participants were doing it correctly, but without giving any indication that it resembled the balancing gesture. Experimenters would ensure participants were doing it correctly before leaving, correcting participants if they were moving too quickly or slowly or if their hands were not in the correct position (e.g. 
hands vertical, or palms partially closed). Participants were told that the computer will prompt them when they need to mimic the motion by stating "please mimic the motion until this disappears"

After being given the embodiment condition, the experimenter would leave the room and participants would begin the next task on the computer. Participants first chose a personally important issue (Appendix K) and completed the attitude measures which measured their initial attitude strength and their perceived knowledge. Participants were then told that in the next task they would see a $4 \times 4$ matrix and would be allowed to choose 8 of the 16 boxes. They were then shown what the matrix looked like and it was explained that 2 of the rows contained arguments in favour of their 'topic of choice' (topic of choice would be replaced with the actual topic that they chose e.g. same-sex marriage) and 2 of the rows contained arguments against their topic of choice.

Participants then began the information board task. Participants would be prompted with a yellow box stating "please mimic the motion until this message disappears." The yellow box would stay on the screen for 10 seconds. Participants would be able to see the information board, but were unable to click on a box until the message disappeared (Appendix G). Once the box disappeared, participants could select a box at which point an argument would be viewed. Above the argument there was a prompt that told participants to mimic the motion while they read the argument. Once participants read the argument they would be able to click 'next', at which point they would rate the argument, measured on a scale of 1 (very weak argument) to 100 (very strong argument). Once participants indicated their rating of the argument, they would be brought back to the initial $4 \times 4$ matrix. Once again a yellow box prompting participants to mimic 
the motion would be displayed for 10 seconds. The only difference would be that the box they selected in the first round would now be crossed out (Appendix J). Participants would select another box and then read and evaluate the argument. They would repeat this process for a total of 8 times.

Following the information board task, participants were asked what their attitudes towards the issue were, once again on a 1-100 scale $(1=$ indifferent, $100=$ extremely strong). Participants then completed a short filler task from another study (an evaluative conditioning task, Olson \& Fazio, 2004) and then were asked to recall as many arguments from the information board matrix as they could, regardless of whether they agreed or disagreed with them. Following the recall, participants were given a few suspicion questionnaires and also asked to recall which rows were in the information board were in favour of their issue and which rows were against the issue. Participants were then thanked for their participation in the study, given a debriefing sheet, and were thoroughly debriefed. 


\section{RESULTS}




\section{Dataset}

Uncertainty orientation was calculated by subtracting the standardized F-scale scores from the standardized uncertainty scores, resulting in a standardized resultant measure of uncertainty. Following the methodology outlined by the theory of uncertainty-orientation (Sorrentino et al., 1992), a tertile split of the data was performed. The top third of the sample were classified as UOs $(n=57)$, with 30 in the 'down' condition and 27 in the 'up' condition. The bottom third of the sample were classified as COs $(n=58)$, with 30 in the 'down' condition and 28 in the 'up' condition. The middle third, known as moderates were excluded on the basis that they typically exhibit inconsistent patterns (Sorrentino et al., 1992; Sorrentino, 1977; Sorrentino, Smithson, Roney \& Walker, 2003). This resulted in a total of 115 participants, 81 women and 34 men, between the ages of 17 and $35(M=18.66, S D=1.96)$.

Participants were free to choose the issue that was most important to them as well as the direction. Examining only the included participants (i.e. UOs and COs), this resulted in 27 participants choosing same-sex marriage (4 against; 23 in favour), 36 participants choosing abortion (24 pro-choice; 12 prolife), 44 choosing employment equity ( 1 against; 43 in favour), and 8 choosing capital punishment ( 3 against, 5 in favour). The primary results are aggregated across all topics.

To determine whether there were differences in topic selection between UOs and COs, chi-square analyses were examined across topic and whether they were in favour or against the topic. No significant differences were found between topic and uncertainty orientation $\chi^{2}(3)=3.32, p=.35$, nor between uncertainty orientation and whether they 
were in favour or against topics in general $\chi^{2}(1)=.78, p=.37$. Furthermore, assessing each topic separately, no differences were found between uncertainty orientation and whether they were in favour or against the topic for employment equity, $\chi^{2}(1)=.71, p=$ .40 , capital punishment, $\chi^{2}(1)=.04, p=.85$, andsame-sex marriage, $\chi^{2}(1)=.79, p=$ .37 , but there were marginal differences for abortion; $\chi^{2}(1)=3.60, p=.06$, with 8 COs and 16 UOs being prochoice, whereas $8 \mathrm{COS}$ and 4 UOs being prolife.

Similarly, because the embodiment condition was given prior to choosing a topic, analyses were conducted to test for differences among the 'up' and 'down' condition. No differences were found between embodiment condition and topic $\chi^{2}(3)=.91 p=.82$, nor between embodiment and whether they were in favour or against $\chi^{2}(1)=.02, p=.90$, nor for abortion, employment equity, capital punishment, or same-sex marriage, $\chi^{2}(1)=$ $2.06 p=.15, \chi^{2}(1)=.93, p=.34, \chi^{2}(1)=1.43 p=.29, \chi^{2}(1)=.06 p=.93$, respectively.

Lastly it is important to note that those who exhibited the most biased searching, (e.g. chose 8 congruent arguments), were unable to be included in the biased assimilation or disconfirmation bias analyses. This is because a repeated measures analysis requires data to be present for both variables, and these individuals $(n=5)$ who did not look at incongruent information do not have data for that side of the issue.

Thus the analyses for biased assimilation and the disconfirmation bias can be viewed as 
conservative $^{3}$. Additionally, these 5individuals did not differ from the main sample across levels of the embodiment manipulation $\chi^{2}(1)=1.62, p=.20$ (4 and 1 for 'down' and 'up' respectively), or levels of uncertainty orientation $\chi^{2}(1)=.228, p=.63$ (2 and 3 for COs and UOs respectively).

\section{Selective Exposure}

Primary Analyses. Figure 1 illustrates the pattern of interaction between uncertainty orientation and the embodiment conditions on selective exposure. As predicted, UOs selected fewer congruent arguments $(M=4.26, S E=.24)$ in the 'up' condition than $\operatorname{COs}(M=4.71, S E=.22)$ and this difference was greater than in the 'down' condition where UOs have higher selective exposure scores $(M=4.67, S E=.24)$, than $\operatorname{COs}(M=4.63, S E=.22)$ conditions, A t-test of this pattern of interaction was not significant $t(111)=1.06, p=.29$. Comparisons within this pattern of interaction revealed that there was a marginally significant difference for UOs versus COs in the 'up' condition, $t(111)=1.38, p=.09$, one-tailed, but no difference in the down condition, $t$ $(111)=.11 p=.46$, one tailed.

Additional analyses revealed no significant effects for the embodiment by uncertainty orientation interaction when controlling for attitude strength, $F(1,110)=$ $.696, p=.41$ or knowledge $F(1,110)=.54, p=.46$.Examining the main effects, there

\footnotetext{
${ }^{3}$ It is suggested that those who chose only congruent arguments would be more biased than those who did not. Thus eliminating them would, if anything, show less of an effect. Follow up tests revealed that while the difference of ratings of arguments congruent with one's position between individuals who chose all congruent arguments $(M=68.62, \mathrm{SD}=11.94)$, and participants who chose at least 1 incongruent argument $(M=66.73, S D=14.66)$ was higher, it was not significant $t(113)=-.28, p=.78$; However when examining the disconfirmation bias, participants that picked all congruent information were marginally significantly faster reading congruent arguments $(M=8.57, S D=3.34)$ than those who chose at least 1 incongruent argument $(M=13.84, S D=6.84), \mathrm{t}(113)=1.70, \mathrm{p}=.09$
} 
was no

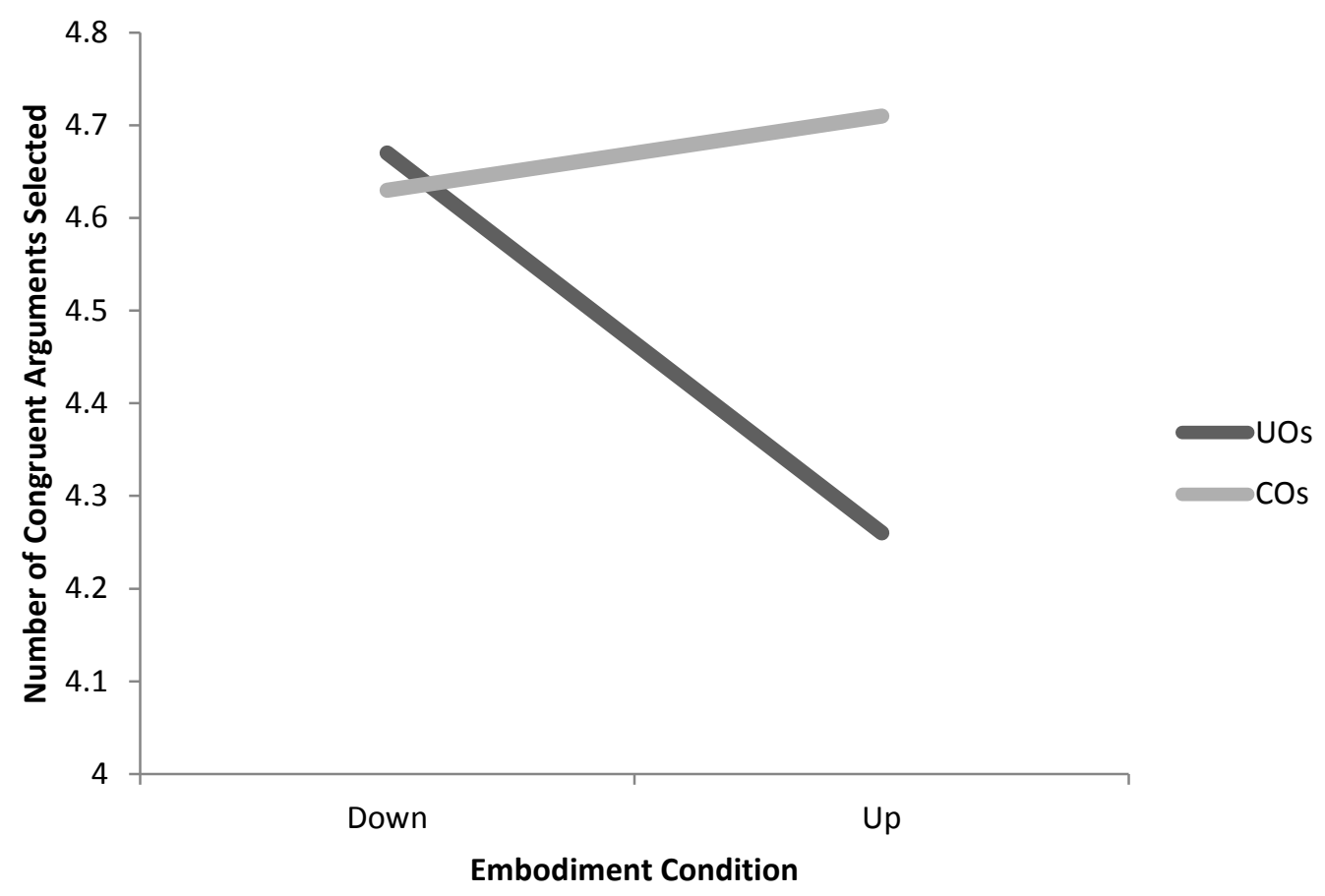

Figure 1. Shows the number of congruent arguments selected for UOs and COs for the 'up' and 'down' embodiment conditions. 
significant main effect of uncertainty $F(1,111)=.85, p=.36$, or embodiment condition $F(1,111)=.51, p=.48$.

Additional Analyses. Upon exploring some investigative analyses, a main effect of gender was discovered such that women selected more congruent information, ( $M$ 4.73, $S E=.15)$ than men $(M=4.21 S E=.13) t(113)=2.125, p=.03$. In addition, the pattern shown in Figure 1 appeared stronger for women than men $^{4}$. Figure 2 shows the pattern of interaction for females. UOs in the 'up' condition selected fewer congruent arguments $(M=4.21, S E=.30)$, than COs, $(M=5.11, S E=.31$ and this difference was greater than in the down condition $(M=4.76, S E=.29)$ for UOs vs. COs $(M=4.83, S E$ $=.28$ ). A one-way test of the pattern of interaction revealed a marginally significant interaction $t(79)=1.42, p=.08$. Examining the interaction reveals that UOs in the 'up' condition selected significantly fewer congruent arguments than COs in the 'up' condition $t(79)=2.08, p=.02$, one-tailed, but not in the down condition $t(79)=.15, p=.44$, onetailed.

Overall Effects. An analysis was conducted to examine whether, overall, participants selectively exposed themselves to information they agreed with. A t-test between the average number of congruent arguments selected $(M=4.57, S D=1.22)$ against a mean of 4 (the number of congruent arguments selected if selection was random) revealed a significant selective exposure effect $t(114)=5.04, p<.001$. Additionally the number of congruent arguments significantly correlated with the amount

\footnotetext{
${ }^{4}$ The interaction between embodiment condition, uncertainty orientation and gender was non-significant $F$ $(1,107)=.60, p=.44$. Examining gender for the other dependent variables revealed no meaningful effects.
} 
of self-perceived knowledge, $r=.22, p=.02$ and marginally with initial attitude strength $r=.18, p=.06$. It should also be noted that gender did note correlate with initial attitude strength or knowledge $r=. .12, p=.20$ and $r=.14, p=.13$ respectively. 


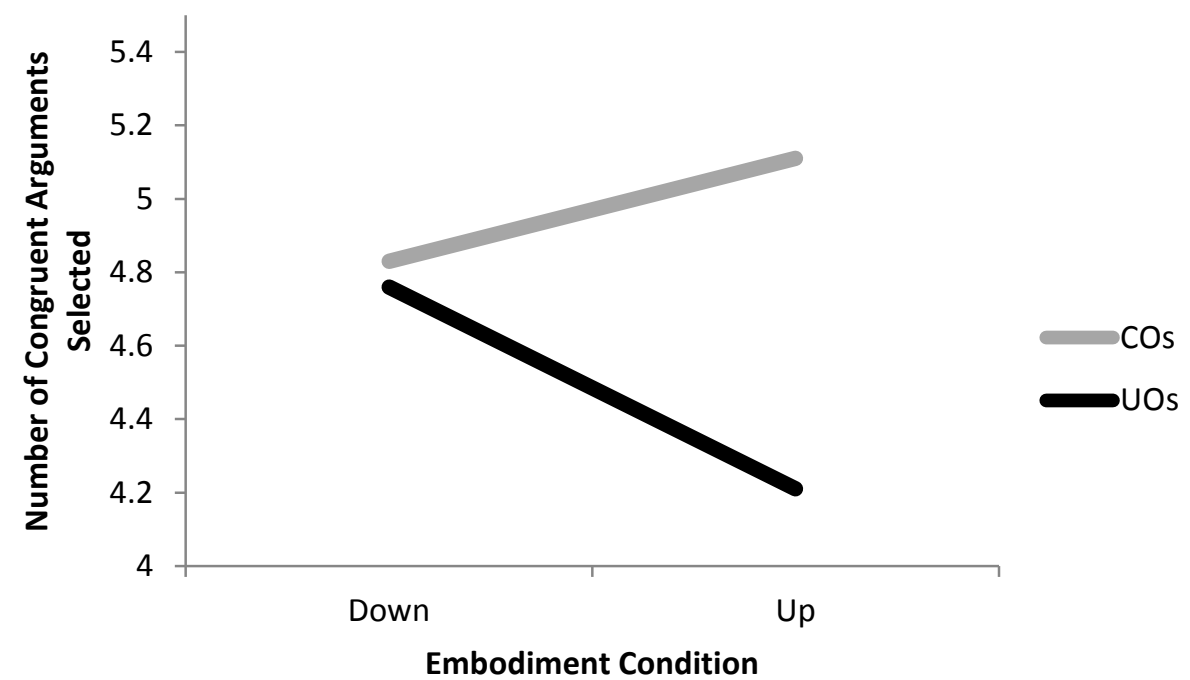

Figure 2.Shows the number of congruent arguments selected for UOs and COs for the 'up' and 'down' embodiment conditions. for women only 


\section{Biased Assimilation}

Primary Analyses. Figure 3depicts the results associated with the main hypothesis that UOs would express less biased assimilation in the 'up' versus 'down' condition as compared to COs. A repeated measures analysis was conducted examining the effect of participant's position, embodiment condition and uncertainty orientation on arguments for and against as the repeated measures variable. The analysis revealed a non-significant four-way interaction, $F(1,102)=.808, p=.37$.Controlling for attitude strength and knowledge, this interaction remains non-significant, $F(1,100)=.62, p=$ .44 .

For a summary of all means and standard deviations across each condition please see Table 1. Examining main effects, there were no significant main effects of argument position, $F(1,102)=.03, p=.96$, uncertainty-orientation $F(1,102)=.59, p=.45$, embodiment condition $F(1,102)=.60, p=.44$

Overall Effects. To test whether participants showed biased assimilated of the information, a repeated measures analysis was conducted on the average argument strength for arguments in favour of the issue and the average argument strength for arguments against the issue between participant position. The analysis revealed a significant interaction between whether participants were in favour or against the issue and whether the argument was in favour or against the issue $F(1,108)=53.39, p<.001$, such that participants in favour of the issue rated arguments in favour of the issue $(M=$ 66.41, $S D=14.99)$ higher than arguments against $(M=42.92, S D=22.46), t(35)^{5}=5.01$,

\footnotetext{
${ }^{5}$ Levene's test violated, $F(1,108)=9.50, p=.004$
} 
$p<.001$, and those who were against the issue rated arguments against the issue $(M=$

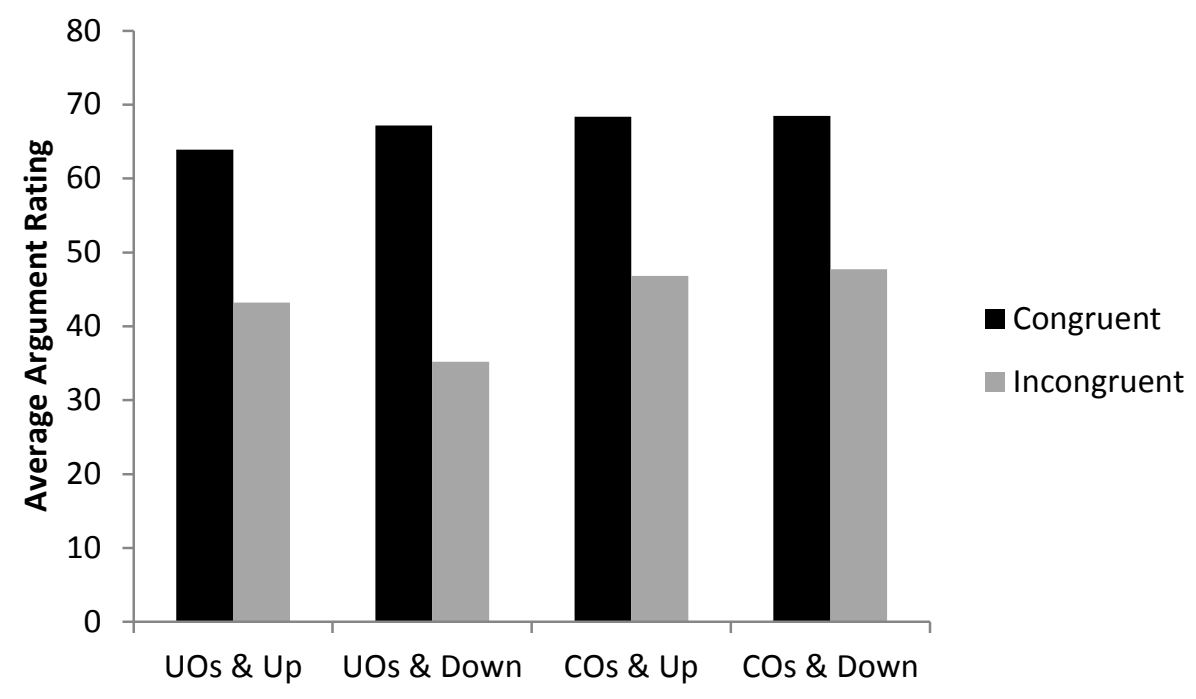

Figure 3. The four way interaction between uncertainy orientation, the embodiment conditions, argument direction, and participant position on average argument ratings. 


\begin{tabular}{ccccccccc}
\hline & $\begin{array}{c}\text { Argument In } \\
\text { Favour \& } \\
\text { Participant In } \\
\text { favour }\end{array}$ & $\begin{array}{c}\text { Argument In } \\
\text { Favour \& } \\
\text { Participant } \\
\text { Against }\end{array}$ & $\begin{array}{c}\text { Argument } \\
\text { Against \& } \\
\text { Participant In } \\
\text { favour }\end{array}$ & $\begin{array}{c}\text { Argument } \\
\text { Against \& } \\
\text { Participant } \\
\text { Against }\end{array}$ \\
\hline UOs \& Up & 61.66 & $(11.49)$ & 50.70 & $(14.94)$ & 35.74 & $(17.91)$ & 66.10 & $(18.00)$ \\
UOs \& Down & 64.72 & $(19.88)$ & 36.88 & $(21.42)$ & 33.56 & $(19.90)$ & 69.60 & $(10.07)$ \\
COs \& Up & 70.55 & $(13.44)$ & 42.62 & $(29.27)$ & 51.00 & $(26.52)$ & 66.17 & $(16.94)$ \\
COs \& Down & 68.17 & $(14.20)$ & 46.25 & $(27.26)$ & 49.20 & $(20.66)$ & 68.74 & $(12.75)$ \\
\hline
\end{tabular}

Table 1

Means and standard deviations for congruent and incongruent argument ratings across argument direction and participant position on each level of uncertainty orientation and embodiment condition. Higher numbers indicate higher average argument ratings. 
69.01, $S D=16.28)$, higher than arguments in favour of the issue $(M=43.44, S D=$ 22.71), $t(92)^{6}=7.16, p<.001$. Furthermore, there were no differences between average ratings in favour $(M=54.92, S D=19.90)$ or against $(M=55.35, S E=2.21)$ the issue, $\mathrm{F}$ $(1,104)=.014, p=.91($ Figure 4$)$.

\section{Disconfirmation Bias}

Primary Analyses. Figure 5 reveals the pattern of interactions across embodiment and uncertainty conditions on time spent reading arguments. Examining the hypothesis that UOs would exhibit a greater reduction in bias in the 'up' versus 'down' condition compared to COs, a repeated measures analysis was conducted examining the effect of participant's position, embodiment condition and uncertainty orientation on time spent reading arguments for and against the issues. The test of this pattern of interaction was non-significant, $F(1,102)=.05, p=.85$.This interaction remains non-significant when controlling for time spent reading the instructions, $F(1,101)=.06, p=.80$, initial attitude strength, $F(1,101)=.05, p=.83$, or perceived knowledge, $F(1,101)=.04, p=$ .84. In addition, there was no main effect of uncertainty orientation $F(1,102)=$ $1.14, p=.29$ or embodiment condition $F(1,102)=.53, p=.47$. For a list of all means and standard deviations across each condition please see Table 2.

It should be noted that the arguments for employment equity were taken from the Taber and Lodge (2006) study. As such, they were considerably longer than the other arguments and thus participants spent longer reading them $(M=19.35, S D=6.52)$ than

\footnotetext{
${ }^{6}$ Levene's test violated, $F(1,108)=8.45, p=.003$
} 


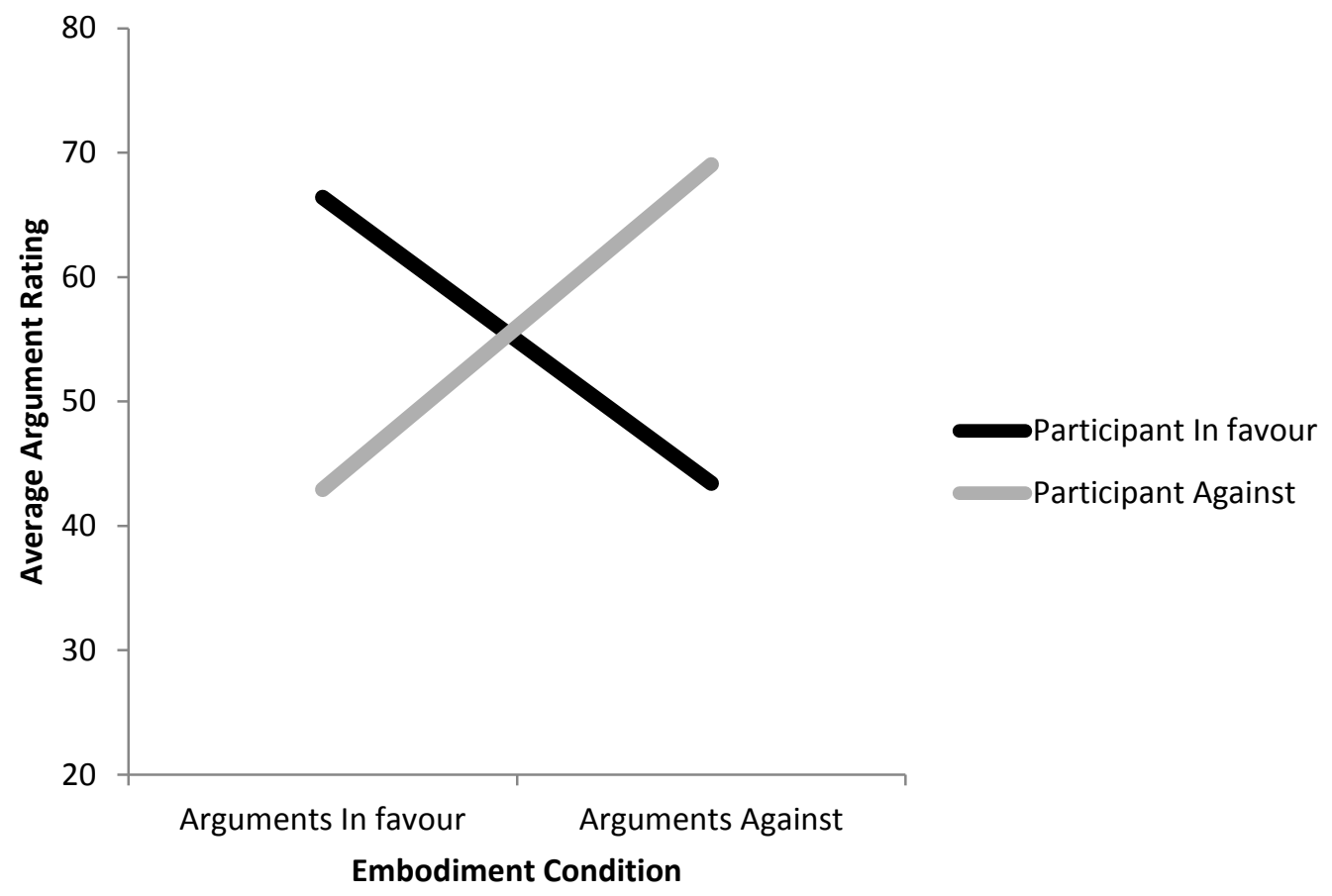

Figure 4. Overall biased assimilation examining argument direction, and participant position on average argument ratings. 


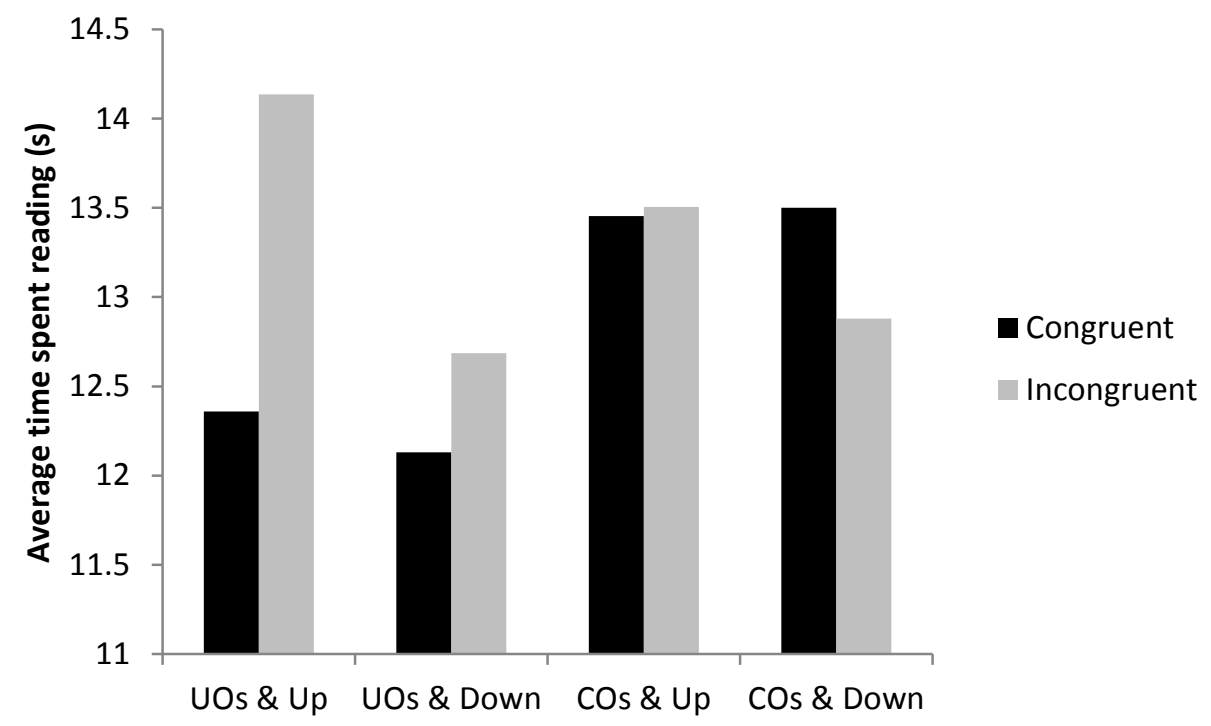

Figure 5. The four way interaction examining time spent reading between uncertainy orientation, the embodiment conditions, argument direction, and participant position for all topics. Time is measured in seconds. 
Table 2

Means and standard deviations for time spent reading for congruent and incongruent argument ratings across argument direction and participant position on each level of uncertainty orientation and embodiment condition. Time is measured in seconds.

\begin{tabular}{ccccccccc}
\hline & $\begin{array}{c}\text { Argument In } \\
\text { Favour \& } \\
\text { Participant In } \\
\text { favour }\end{array}$ & $\begin{array}{c}\text { Argument In } \\
\text { Favour \& } \\
\text { Participant } \\
\text { Against }\end{array}$ & $\begin{array}{c}\text { Argument } \\
\text { Against \& } \\
\text { Participant In } \\
\text { favour }\end{array}$ & $\begin{array}{c}\text { Argument } \\
\text { Against \& } \\
\text { Participant } \\
\text { Against }\end{array}$ \\
\hline UOs \& Up & 14.50 & $(6.24)$ & 9.10 & $(2.45)$ & 19.17 & $(9.72)$ & 10.22 & $(2.52)$ \\
& & & $M$ & $(S D)$ & $M$ & $(S D)$ & $M$ & $(S D)$ \\
UOs \& Down & 15.07 & $(7.16)$ & 9.66 & $(2.77)$ & 15.71 & $(7.84)$ & 9.19 & $(1.81)$ \\
COs \& Up & 15.13 & $(6.80)$ & 10.52 & $(4.71)$ & 16.49 & $(8.34)$ & 11.78 & $(6.74)$ \\
& & & & & & & & \\
COs \& Down & 15.07 & $(8.80)$ & 7.96 & $(1.66)$ & 17.8 & $(11.66)$ & 11.93 & $(3.63)$ \\
\hline
\end{tabular}


the other arguments $(M=10.06, S D=3.93), t(62)=8.47, p<.001$, Levene's test violated, $F(1,113)=8.04 p=.005$. Because participants chose an overwhelming majority of in favour arguments for employment equity, this resulted in a significant main effect of argument type time for argument in favour, $F(1,102)=9.13, p=.003$. As such, analyses were re-examined without employment equity.

Additional Analyses. Removing employment equity from the analysis still reveals a non-significant pattern of interaction $F(1,58)=.02, p=.88$ (See Figure 6), and the effect of argument position becomes marginal, $F(1,58)=3.52, p=.07$. however this becomes non-significant when controlling for time reading for instructions $F(1,57)=$ $2.20, p=.14$.

The main effect of embodiment condition was non-significant $F(1,58)=.002, p$ $=.97$, as was uncertainty orientation, $F(1,58)=1.81, p=.18$. In addition the four way pattern of interaction remains nonsignificant when controlling for time reading instructions $F(1,57)=.10, p=.76$.

Overall Effects. To test whether participants exhibited an overall disconfirmation bias, a repeated measures analysis was conducted on the average time spent reading arguments in favour of the issue and the average time spent reading for arguments against the issue across participant position. The results showed no evidence of a disconfirmation bias, $F(1,108)=.99, p=.32$ and remains non-significant when removing employment equity $F(1,64)=.84, p=.36$. In addition, the effect remains nonsignificant when controlling for time reading instructions $F(1,107)=.96, p=.33$ and $F(1,63)=.71, p=.40$ for the entire sample and when removing employment equity respectively. 


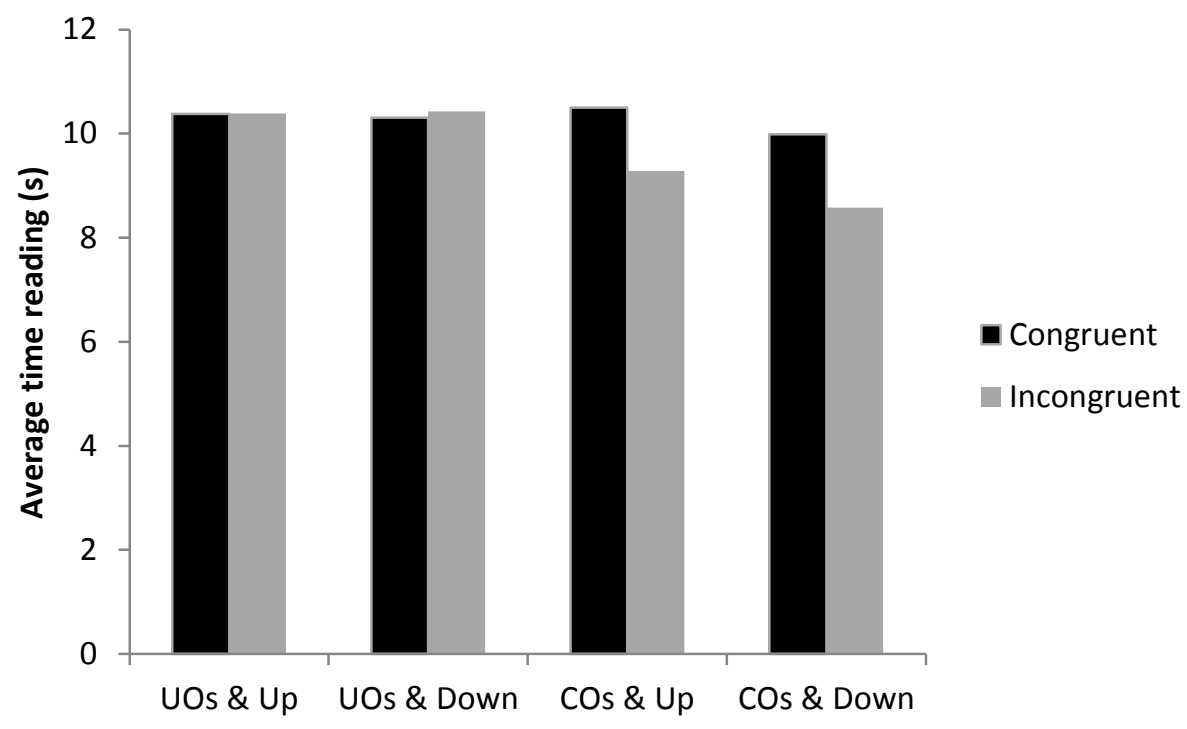

Figure 6. The four way interaction examining time spent reading between uncertainy orientation, the embodiment conditions, argument direction, and participant position without arguments for or against employment equity. Time is measured in seconds 
Table 3.

Means and standard deviations for time spent reading for congruent and incongruent argument ratings across argument direction and participant position on each level of uncertainty orientation and embodiment condition without employment equity. Time is measured in seconds.

\begin{tabular}{ccccccccc}
\hline & $\begin{array}{c}\text { Argument In } \\
\text { Favour \& } \\
\text { Participant In } \\
\text { favour }\end{array}$ & $\begin{array}{c}\text { Argument In } \\
\text { Favour \& } \\
\text { Participant } \\
\text { Against }\end{array}$ & $\begin{array}{c}\text { Argument } \\
\text { Against \& } \\
\text { Participant In } \\
\text { favour }\end{array}$ & $\begin{array}{c}\text { Argument } \\
\text { Against \& } \\
\text { Participant } \\
\text { Against }\end{array}$ \\
\hline & $M$ & $(S D)$ & $M$ & $(S D)$ & $M$ & $(S D)$ & $M$ & $(S D)$ \\
\hline UOs \& Up & 10.53 & $(3.43)$ & 9.10 & $(2.44)$ & 11.67 & $(3.91)$ & 10.22 & $(2.52)$ \\
UOs \& Down & 11.42 & $(5.85)$ & 9.66 & $(2.76)$ & 11.20 & $(4.79)$ & 9.20 & $(1.81)$ \\
COs \& Up & 10.38 & $(2.97)$ & 8.90 & $(2.14)$ & 9.66 & $(2.73)$ & 10.61 & $(6.56)$ \\
COs \& Down & 8.04 & $(3.28)$ & 7.96 & $(1.67)$ & 9.19 & $(4.81)$ & 11.93 & $(3.63)$ \\
\hline
\end{tabular}




\section{Selective Recall}

Primary Analyses. Figure 7 shows the pattern of interaction across each condition of embodiment and uncertainty orientation for recall of congruent and incongruent arguments. Examining the hypothesis that selective recall would interact with the embodiment condition and uncertainty orientation showed no significant interaction $F(1,102)=.08, p=79$. In addition, the main effect of uncertainty orientation was not significant $F(1,102)=1.02 p=.31$, nor that of embodiment condition $F(1,102)=.16, p=.61$.For a summary of all means and standard deviations across each condition please see Table 4

Overall Effects of Selective Recall. Figure 8 shows the pattern of interaction for the overall effects of selective recall. A repeated measures analysis was conducted on arguments recalled (in favour and against) between individuals who declared themselves as in favour or against the issue. The results showed evidence of selective recall, $F$ (1, $108)=12.36, p=.001$. Examining post-hoc tests reveal that individuals who were in favour of the issue recalled significantly more arguments against the issue $(M=.38, S D=$ $.37)$, than arguments for the issue $(M=.20, S D=.21) . t(33)=2.38, p=.02$, Levene's test violated $F(1,108)=31.45, p<.001$. However, although those who were against the position didrecall more arguments in favour $(M=.30, S D=.30)$, than arguments against $(M=.23, S D=.25)$, this difference was not significant $t(108)=1.103, p=.27$. Furthermore, there was no main effect of argument position $F(1,108)=.50, p=.48$. 


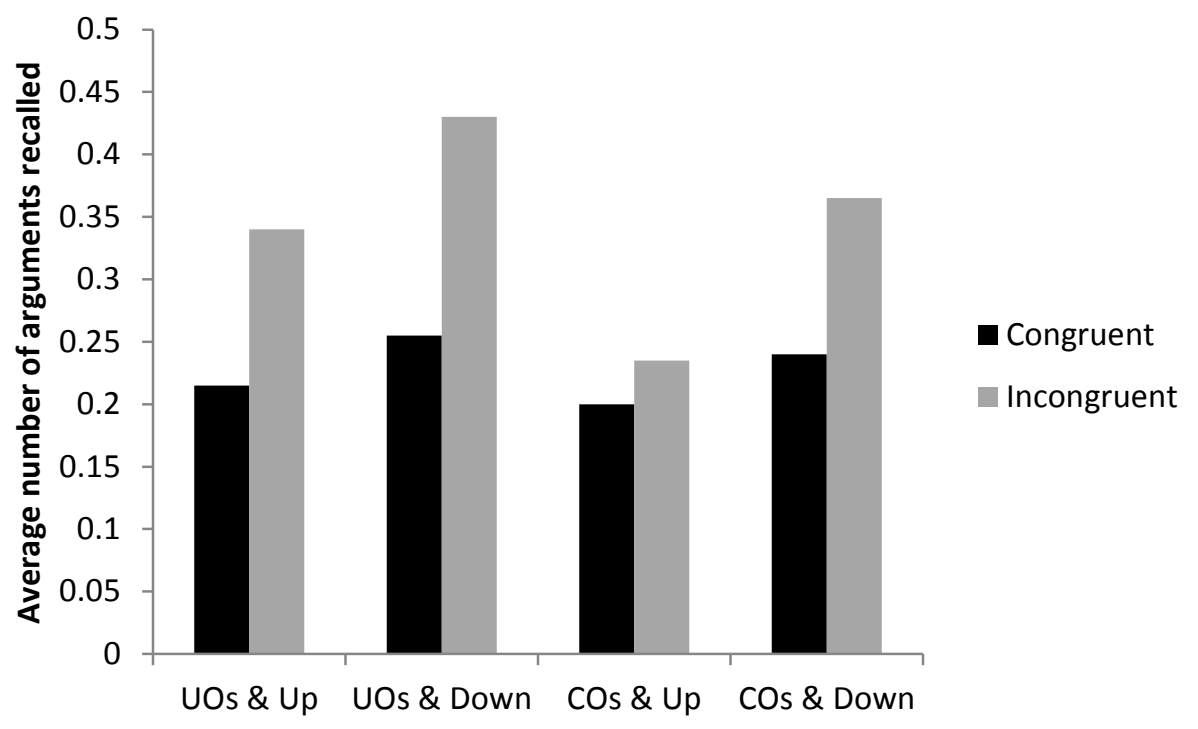

Figure 7. The four way interaction examining average arguments recalled between uncertainy orientation, the embodiment conditions, argument direction, and participant position across all topics. Number of arguments recalled is divided by number of arguments viewed. 
Table 4

Means and standard deviations for average arguments recalled for congruent and incongruent argument ratings across argument direction and participant position on each level of uncertainty orientation and embodiment condition. Number of arguments recalled is divided by number of arguments viewed.

\begin{tabular}{|c|c|c|c|c|c|c|c|c|}
\hline & \multicolumn{2}{|c|}{$\begin{array}{l}\text { Argument In } \\
\text { Favour \& } \\
\text { Participant In } \\
\text { favour }\end{array}$} & \multicolumn{2}{|c|}{$\begin{array}{l}\text { Argument In } \\
\text { Favour \& } \\
\text { Participant } \\
\text { Against }\end{array}$} & \multicolumn{2}{|c|}{$\begin{array}{c}\text { Argument } \\
\text { Against \& } \\
\text { Participant In } \\
\text { favour }\end{array}$} & \multicolumn{2}{|c|}{$\begin{array}{c}\text { Argument } \\
\text { Against \& } \\
\text { Participant } \\
\text { Against }\end{array}$} \\
\hline & $M$ & $(S D)$ & $M$ & $(S D)$ & $M$ & $(S D)$ & $M$ & $(S D)$ \\
\hline UOs \& Up & .23 & $(.25)$ & .39 & $(.43)$ & .29 & $(.27)$ & .20 & $(.21)$ \\
\hline UOs \& Down & .33 & $(.21)$ & .46 & $(.42)$ & .40 & $(.30)$ & .18 & $(.18)$ \\
\hline COs \& Up & .17 & $(.17)$ & .17 & $(.24)$ & .30 & $(.33)$ & .23 & $(.29)$ \\
\hline COs \& Down & .11 & $(.16)$ & .50 & $(.37)$ & .23 & $(.31)$ & .37 & $(.30)$ \\
\hline
\end{tabular}




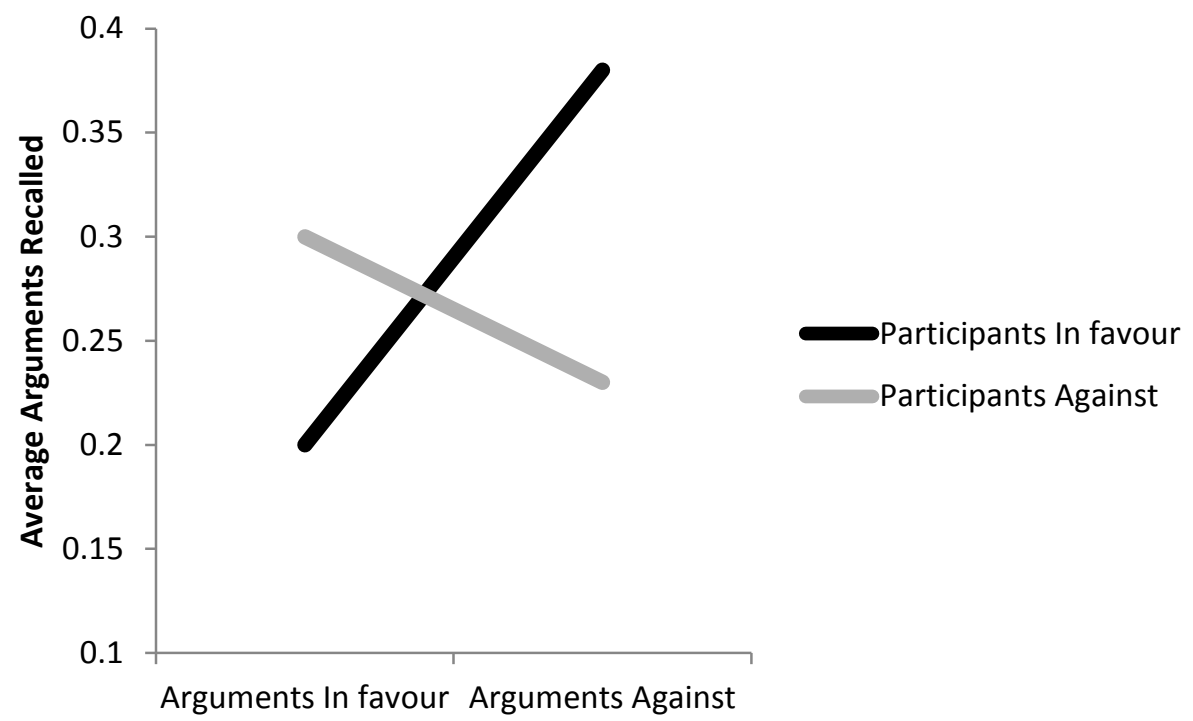

Figure 8. Interaction between argument direction and participant position for selective recall. 


\section{Attitude Polarization}

Primary Analyses. Figure 9, depicts the overall interaction between attitude polarization between uncertainty orientation and embodiment on attitude polarization, when initial attitudes are covaried. As can be seen, only the UOs in the 'up' condition showed any sort of depolarization of attitudes $(M=-1.92, S D=10.85)$ whereas COs showed the greatest polarization of attitudes $(M=5.21, S D=15.52)$ with the difference between UOs and COs greater than in the down condition, $(M=2.23, S D=13.35$ and $M$ $=4.37, S D=12.22$ for UOs and COs respectively).

A one-tailed t-test of the predicted pattern of interaction was significant, $t(111)=$ $1.90, p=.04$. Tests reveal that UOs differ significant from COs in the 'up' condition $t$ $(111)=2.36, p=.01$, one-tailed, but not in the down condition $t(111)=.26, p=.80$.In testing for overall effects, there was no significant main effect of embodiment condition $F(1,111)=.46, p=.50$ but there was a marginally significant main effect of uncertainty $F(1,111)=3.59, p=.06$ with UOs polarizing less overall $(M=.26, S D=12.30)$ than $\operatorname{COs}(M=4.78, S D=13.80)$.

Overall Effects of Attitude Polarization. To examine whether participants exhibited attitude polarization, participants' initial attitudes $(M=63.36, S D=24.37)$ and their attitudes at the end of the information board task $(M=65.90, \mathrm{SD}=21.99)$, were compared using a paired t-test $\mathrm{t}(113)=-2.060, p=.04$, indicating an overall attitude polarization effect. 


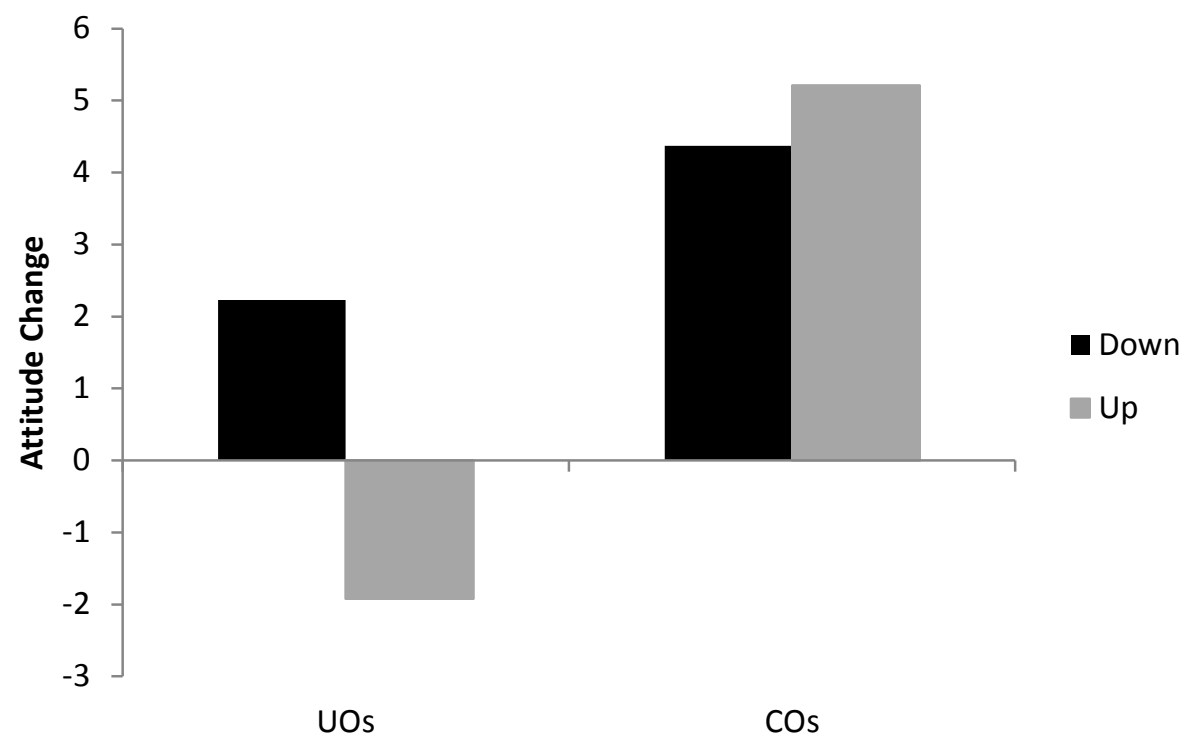

Figure 9. Analysis of the interaction of attitude polarization between uncertainty orientation and embodiment manipulation. Attitude polarization is depicted as a difference score between initial attitude strength subtracted from attitude strength following the information board task. 


\section{DISCUSSION}


Overall, the results testing the general hypothesis were weak. In most instances results trended in the hypothesized direction, but they often failed to reach significance. Two results, however, do offer encouragement for future research. The first was with respect to attitude polarization. Uncertainty-Oriented individuals show a greater reduction in their attitudes than COs in the 'up' embodiment condition, and this difference was greater than in the down condition.

A second point of encouragement is that the predicted uncertainty orientation $\mathrm{x}$ embodiment interaction did work for females. Here UOs paid more attention to incongruent information than COs in the 'up' condition and this difference was significantly greater than in the 'down' condition. Although males showed the same pattern of interaction, it was not a significant effect. Taken together, it is possible that with a larger sample size, we may have obtained a significant effect for selective exposure and several of the other measures.

Another possibility for weak effects follows from the inconsistency between this work and that by Lee and Schwarz, (2012) who found effects using the 'up' manipulation but not in the neutral or 'down' condition. These investigators examined making a decision between different products or between allocating time between work and leisure It is possible that there may exist a fundamental difference between the balance that exists between making a consumption decision versus the balance that exists when processing information. For example, when making a choice people may want balance in the sense that they give choices equal weight, but when balancing when processing information, people may want to fairly view and interpret the information. 
The results with attitude polarization and selective exposure (with women) follows from the conceptualizations of embodied cognition as similar to that of goal priming. Under this view, embodiment manipulations interact with one's own motivation, which suggests that bodily feedback is more flexible than is currently theorized. However, the way in which embodiment interacts with an individual motivation is still unclear. One possibility is due to the recognition that embodiment, and individual differences in motivation both work through construct accessibility (Kruglanski et al., 2002; Higgins \& King, 1981; Bargh \& Pratto, 1986), Thus the balance prime can be more fluently incorporated into individuals who have greater accessibility towards resolving uncertainty, resulting in UOs being more affected by the manipulation than COs. Regardless, individual differences appear to have an important effect regarding embodiment findings and as such research focusing on individual differences is necessary for a full understanding of embodied cognition and conceptual metaphor theory. Future research may seek to examine this interaction in a CO-centric society, such as Japan, to determine whether this embodiment effect interacts with one's mode of processing. COs in this environment may tend to seek more congruent arguments, with UOs being relatively unaffected.

In addition, it is interesting that there was no main effect of uncertainty orientation. One reason for this may stem from the idea that the 'down' condition may have served as the embodiment manipulation and interacted with uncertainty orientation in different ways. The motion of alternately moving one's hands 'down' can also be thought of as embodying avoidance, in that the motion is similar to pushing something away. One of the earliest studies by Solarz (1960) has now been interpreted as an 
embodiment finding, providing some evidence for this argument. In this study, participants were given words like smart, stupid, or happy, and asked to either move a lever towards or away from themselves. Participants were faster moving the lever towards themselves for positive words than for negative words and faster moving the lever away from themselves for negative words. These results were also replicated and then extended by Chen and Bargh (1999) who also showed that the same effects occur even when participants are not evaluating the stimuli (e.g. they are always pulling or always pushing). Since the motion of pushing away is related to avoidance of negative stimuli, this may have interacted with UOs and activated avoidance concepts which inherently primed UOs to avoid incongruent information. As such, UOs who may normally have expressed less bias than COs, became more avoidant under the 'down' condition and as such expressed similar amounts of bias to COs.

Lastly, this research adds to the wealth of research on the biasing effect of attitudes on information processing. Participants tended to selectively expose themselves to information and this effect was greater the more self-perceived knowledge one had or the stronger one's attitudes. Participants also weighed information they agreed with as stronger than information they disagreed. They also recalled more incongruent information on average, than congruent information, which demonstrates expectancy violations and a tendency to spend more time on incongruent information (Eagly, Chen, Chaiken, \& Shaw-Barnes, 1999; Edwards and Smith). Lastly participants exhibited a significant attitude polarization effect. 
Limitations and Future Directions. It should be noted that Lee and Schwarz (June $2^{\text {nd }}, 2011$ Personal Communication) had two control conditions (the hands 'down' condition, and a hands 'up' but stationary), however they did not find any differences between the two conditions. In addition, the present research was mainly interested in whether UOs would differ from COs in the balanced condition as opposed to the nonbalanced condition. As such it was opted to only use one control to increase power. Furthermore, because the task in this study was cognitively demanding, it was thought that irrespective of an embodiment effect, the movement of one's hands would be disrupting and depleting. Indeed, many participants in debriefing and in suspicions questions noted that they were distracted. As such, it was thought that a completely neutral condition or the stationary hands 'up' condition would not provide a suitable control for this task. It may be wondered why Lee and Schwarz did not find effects between the two control condition. One reason could be that those experiments did not take into account uncertainty orientation, which appear to play an interacting role between the 'up' and 'down' condition and as such may explain why no effects were found.

In addition, it may be wondered why there is no main effect of the embodiment manipulation. Two reasons are suggested. The first is that previous research using this manipulation did not take into account uncertainty orientation, which appears to have differing impacts on UOs and COs. As such, it is possible that other samples had a greater percentage of uncertainty-orientated individuals. The second is that a number of participants were unable to recall which rows were congruent with their views and which rows were not following the information board task, suggesting that they were not 
involved with the task. When eliminating these participants, analyses do reveal a significant main effect of embodiment condition

A limitation in this study was that participants were free to control many of the variables, for example, the topic they chose and the arguments they view. In addition, participants varied widely with respect to their attitudes and knowledge, resulting in even greater variance. The results often trended in the predicted direction or were significant for specific populations (e.g. women), however, this freedom may have weakened the statistical power of the manipulation. Future studies may want to explore this effect of uncertainty orientation and embodiment using greater sample sizes or controlling attitudes and knowledge and the information participants view.

Lastly, participants were given the opportunity to choose their own topic in order to keep personal relevance high for all participants. Previous research has shown that uncertainty orientation interacts with personal relevance. It is possible that if the topics were of low personal relevance, the interactions would have been reversed, with COs being more balanced in the 'up' condition. Future research should examine manipulating personal relevance in order to better understand how the confirmation bias and embodying balance interacts with uncertainty orientation.

Conclusion. This paper sought to explore the moderating effect of uncertainty orientation and embodied metaphor on the confirmation bias. In doing so, it attempted to contribute to the literature by examining ways to reduce the confirmation and explore mechanisms of embodied cognition through individual differences. Although the overall results are weak, what was found is suggestive of the factthat embodiment, like priming, 
interacts with people's inherent motivations. Future research will test this possibility and perhaps aid in understanding the underlying dynamics of embodied cognition and conceptual metaphor theory. 


\section{References}

Aarts, H., Custers, R., \& Veltkamp, M. (2008).Goal priming and the affectivemotivational route to nonconscious goal pursuit. Social Cognition, 26(5), 555-577.

Albarracin, D., \& Mitchell, A. L. (2004). The role of defensive confidence in preference for proattitudinal information: How believing that one is strong can sometimes be a defensive weakness. Personality and Social Psychology Bulletin, 30(12), 1565-1584.

Allport, G. W. (1954). The nature of prejudice. Oxford, England: Addison-Wesley. Asch, S. E. (1946) Forming impressions of personality, Journal of Abnormal and Social Psychology, 41, 258-290.

Altemeyer, B. (1996). The authoritarian specter. Cambridge, MA, US: Harvard University Press, Cambridge,

Aronson, E. (1968). Dissonance theory: Progress and problems. InR. P. Abelson, E. Aronson, W. J. McGuire, T. M. Newcomb, M. J.Rosenberg, \& P. H. Tannenbaum (Eds.), Theories of cognitive consistency: A sourcebook (pp. 5-27). Chicago: Rand McNally.

Asch, S. E. (1958). The metaphor: A psychological inquiry. In R. Tagiuri\& L. Petrullo (Eds.), Person perception and interpersonal behavior (pp. 86-94). Stanford, CA: Stanford University Press.

Bacon, F. (1939).Novumorganum.In Burtt, E. A. (Ed.), The English philosophers from Bacon to Mill (pp. 24-123). New York: Random House. (Original work published in $1620)$. 
Bandura, A. (1997). Self-efficacy: The exercise of control; self-efficacy: The exercise of control. New York, NY, US: W H Freeman/Times Books/ Henry Holt \& Co, New York, NY.

Bargh, J. A., Chen, M., \& Burrows, L. (1996). Automaticity of social behavior: Direct effects of trait construct and stereotype activation on action. Journal of Personality and Social Psychology, 71(2), 230-244.

Bargh, J. A., Gollwitzer, P. M., Lee-Chai, A., Barndollar, K., \& Trotschel, R. (2001). The automated will: Nonconscious activation and pursuit of behavioral goals.Journal of Personality and Social Psychology, 81(6), 1014-1027.

Bargh, J. A., \& Pratto, F. (1986). Individual construct accessibility and perceptual selection. Journal of Experimental Social Psychology, 22(4), 293-311.

Barsalou, L. W. (1999). Perceptual symbol systems. Behavioral and Brain Sciences, 22(4), 577-660.

Barsalou, L. W. (2008a). Grounded cognition. Annual Review of Psychology, 59, 617645.

Barsalou, L W. (2008b) Grounding symbolic operations in the brain's modal systems. In Embodied grounding: Social, cognitive, affective, and neuroscientific approaches edited by Semin, Gün R., Smith, Eliot R., 9-42. New York, NY, US:Cambridge University Press,

Baumeister, R. F., \& Newman, L. S. (1994). Self-regulation of cognitive inference and decision processes. Personality and Social Psychology Bulletin, 20(1), 3-19.

Bem, D. J. (1967) Self-Perception: An alternative interpretation of cognitive dissonance phenomena. Psychological Review, 74(3), 183-200. 
Berkowitz, L., \& Devine, P. G. (1989). Research traditions, analysis, and synthesis in social psychological theories: The case of dissonance theory. Personality and Social Psychology Bulletin, 15(4), 493-507.

Brannon, L. A., Tagler, M. J., \& Eagly, A. H. (2007).The moderating role of attitude strength in selective exposure to information. Journal of Experimental Social Psychology, 43(4), 611-617.

Brouwers, M. C., \& Sorrentino, R. M. (1993). Uncertainty orientation and protection motivationtheory: The role of individual differences in health compliance. Journal of Personality and Social Psychology, 65, 102-112.

Bruner, J. S., Goodnow, J. J., \& Austin, G. A. (1956). A study of thinking; A study of thinking. Oxford, England: John Wiley and Sons, Oxford.

Byrne, D. (1964). Repression-sensitization as a dimension of personality. In B. A. Maher (Ed.), Progress in experimental personality research (Vol. 1, pp. 170220). New York: Academic Press.

Cacioppo, J. T., Priester, J. R., \& Berntson, G. G. (1993). Rudimentary determinants of attitudes: II. arm flexion and extension have differential effects on attitudes. Journal of Personality and Social Psychology, 65(1), 5-17.

Cesario, J., Plaks, J. E., \& Higgins, E. T. (2006).Automatic social behavior as motivated preparation to interact. Journal of Personality and Social Psychology,90(6), 893910.

Chapman, L. J., \& Chapman, J. P. (1967).Genesis of popular but erroneous psychodiagnostic observations. Journal of Abnormal Psychology, 72(3), 193-204. 
Chen, M., \& Bargh, J. A. (1999). Consequences of automatic evaluation: Immediate behavioral predispositions to approach or avoid the stimulus. Personality and Social Psychology Bulletin, 25(2), 215-224.

Cohen, G. L., Aronson, J., \& Steele, C. M. (2000). When beliefs yield to evidence: Reducing biased evaluation by affirming the self. Personality and Social Psychology Bulletin, 26(9), 1151-1164.

Cooper, J., \& Fazio, R. H. (1984). A new look at dissonance theory. In L. Berkowitz (Ed.), Advances in experimental social psychology ( Vol. 17, pp. 229-264). Odando, FL: Academic Press.

Correll, J., Spencer, S. J., \& Zanna, M. P. (2004). An affirmed self and an open mind: Self-affirmation and sensitivity to argument strength. Journal of Experimental Social Psychology, 40, 350-356.

Cotton, J. L. (1985). Cognitive dissonance in selective exposure. In D. Zillmann \& J. Bryant(Eds.), Selective exposure to communication (pp. 11-33). Hillsdale, NJ: Lawrence Erlbaum Associates.

Damasio, A. R., Tranel, D., \& Damasio, H. (1993). Similarity of structure and the profile of visual recognition defects: A comment on gaffan and heywood.Journal of Cognitive Neuroscience, 5(3), 371-372.

Darley, J. M., \& Gross, P. H. (1983).A hypothesis-confirming bias in labeling effects. Journal of Personality and Social Psychology, 44(1), 20-33.

Dawson, E., Gilovich, T., \& Regan, D. T. (2002). Motivated reasoning and performance on the Wason selection task. Personality and Social Psychology Bulletin, 28, 1379-1387. 
Dijksterhuis, A., \&Aarts, H. (2010). Goals, attention, and (un)consciousness. Annual Review of Psychology, 61, 467-490.

Devine, P. G., Hirt, E. R., \&Gehrke, E. M. (1990). Diagnostic and confirmation strategies in trait hypothesis testing. Journal of Personality and Social Psychology,58(6), 952963.

Ditto, P. H., \& Lopez, D. F. (1992). Motivated skepticism: Use of differential decision criteria for preferred and nonpreferred conclusions. Journal of Personality and Social Psychology, 63(4), 568-584.

Driscoll, D. M., Hamilton, D. L., \& Sorrentino, R. M. (1991).Uncertainty orientation and recall of person-descriptive information. Personality and Social Psychology Bulletin, 17(5), 494-500.

Duclos, S. E., Laird, J. D., Schneider, E., Sexter, M., Stern, L., \& Van Lighten, O. (1989). Emotion-specific effects of facial expressions and postures on emotional experience. Journal of Personality and Social Psychology, 57(1), 100-108.

Eagly, A. H., Chen, S., Chaiken, S., \& Shaw-Barnes, K. (1999). The impact of attitudes on memory: An affair to remember. Psychological Bulletin, 125(1), 64-89.

Edwards K, Smith E. E. (1996). A disconfirmation bias in the evaluation of arguments. Journal ofPersonaliy and Social Psychology. 71, 5-24.

Evans, J. H., Bryson, B., \& DiMaggio, P. (2001). Opinion polarization: Important contributions, necessary limitations. American Journal of Sociology, 106(4), 944959.

Festinger, L. (1957). A theory of cognitive dissonance; A theory of cognitive dissonance Stanford University Press. 
Fischer, P., Jonas, E., Frey, D., \& Schulz-Hardt, S. (2005). Selective exposure to information: The impact of information limits. European Journal of Social Psychology, 35(4), 469-492.

Forster, J., Liberman, N., \& Friedman, R. S. (2007). Seven principles of goal activation: A systematic approach to distinguishing goal priming from priming of non-goal constructs. Personality and Social Psychology Review, 11(3), 211-233.

Gallese, V., Keysers, C., \& Rizzolatti, G. (2004).A unifying view of the basis of social cognition. Trends in Cognitive Sciences, 8(9), 396-403.

Gibbs, R. W. (2006). Metaphor interpretation as embodied simulation. Mind \& Language, 21(3), 434-458.

Glenberg, A. M. (1997). In Ward T. B., Smith S. M. and Vaid J. (Eds.), Mental models, space, and embodied cognition; creative thought: An investigation of conceptual structures and processes. Washington, DC, US: American Psychological Association, Washington, DC.

Glenberg, A. M., \& Kaschak, M. P. (2002).Grounding language in action. Psychonomic Bulletin \& Review, 9(3), 558-565

Harmon-Jones, E., Gerdjikov, T., \& Harmon-Jones, C. (2008). The effect of induced compliance on relative left frontal cortical activity: A test of the action-based model of dissonance. European Journal of Social Psychology, 38(1), 35-45.

Hart, W., \& Albarracin, D. (2009).The effects of chronic achievement motivation and achievement primes on the activation of achievement and fun goals. Journal of Personality and Social Psychology, 97(6), 1129-1141. 
Hart, W., Albarracin, D., Eagly, A. H., Brechan, I., Lindberg, M. J., \& Merrill, L. (2009). Feeling validated versus being correct: A meta-analysis of selective exposure to information. Psychological Bulletin, 135(4), 555-588.

Heider, F. (1958). The psychology of interpersonal relations; the psychology of interpersonal relations. Hoboken, NJ, US: John Wiley \& Sons Inc, Hoboken, NJ.

Hilton, J. L., Klein, J. G., \& von Hippel, W. (1991). Attention allocation and impression formation. Personality and Social Psychology Bulletin, 17(5), 548-559.

Higgins, E. T., \& King, G. (1981) Accessiblity of social constructions: Infomration processing consequences of individual and contextual variaibalitly. IN N. Cantonr \& J.F. Kihlstrong (Eds) Personality, Cognition, and social interaction.

Hodgins, H. S., \& Zuckerman, M. (1993). Beyond selecting information: Biases in spontaneous questions and resultant conclusions. Journal of Experimental Social Psychology, 29(5), 387-407.

Hodson, G., \& Sorrentino, R. M. (1997). Groupthink and uncertainty orientation: Personality differences in reactivity to the group situation. Group Dynamics: Theory, Research, and Practice, 1(2), 144-155.

Hodson, G., \& Sorrentino, R. M. (2001). Just who favors the ingroup? Personality differences in reactions to uncertainty in the minimal group paradigm. Group Dynamics: Theory, Research, and Practice, 2, 92-101.

Hodson, G., \& Sorrentino, R.M. (2003). Uncertainty orientation in the group context: Categorization effects on persuasive message processing. Journal of Social Psychology, 143, 291-312 
IJzerman, H., \& Semin, G. (2009). The thermometer of social relations: Mapping social proximity on temperature. Psychological Science, 20(10), 1214-1220.

Inglis, I. R. (2000). Review: The central role of uncertainty reduction in determining behaviour. Behaviour, 137(12), 1567-1599.

Johnson, M., \& Lakoff, G. (2002). Why cognitive linguistics requires embodied realism. Cognitive Linguistics, 13(3), 245-263.

Jonas, E., Schulz-Hardt, S., Frey, D., \& Thelen, N. (2001). Confirmation bias in sequential information search after preliminary decisions: An expansion of dissonance theoretical research on selective exposure to information. Journal of Personality and Social Psychology, 80(4), 557-571.

Jonas, E., \& Frey, D. (2003).Information search and presentation in advisor-client interaction.

Jonas, E., Greenberg, J., \& Frey, D. (2003). Connecting terror management and dissonance theory: Evidence that mortality salience increases the preference for supporting information after decisions. Personality and Social Psychology Bulletin, 29(9), 1181-1189.

Jonas, E., Schulz-Hardt, S., \& Frey, D. (2005). Giving advice or making decisions in someone elses place: The influence of impression, defense, and accuracy motivation on the search for new information. Personality and Social Psychology Bulletin, 31(7), 977-990.

Jostmann, N. B., Lakens, D., \& Schubert, T. W. (2009).Weight as an embodiment of importance. Psychological Science, 20(9), 1169-1174. 
Jun, N. (2012) Contribution of Internet news use to reducing the influence of selective online exposure on political diversity. Computers in human behavior. 28(4)14501457.

Kahneman, D., \& Tversky, A. (1982).Variants of uncertainty. Cognition, 11(2), 143-157.

Klayman, J., \& Ha, Y. (1987).Confirmation, disconfirmation, and information in hypothesis testing. Psychological Review, 94(2), 211-228.

Koehler, D. J. (1991). Explanation, imagination, and confidence in judgment.Psychological Bulletin. 110(3), 499-519.

Koriat, A., Lichtenstein, S., \&Fischhoff, B. (1980). Reasons for confidence. Journal of Experimental Psychology: Human Learning and Memory, 6(2), 107-118.

Kruglanski, A. W., \& Freund, T. (1983). The freezing and unfreezing of lay-inferences: Effects on impressional primacy, ethnic stereotyping, and numerical anchoring. Journal of Experimental Social Psychology, 19(5), 448-468.

Kruglanski, A. W., Shah, J. Y., Fishbach, A., Friedman, R., Chun, W. Y., \& SleethKeppler, D. (2002). A theory of goal systems. In M. P. Zanna (Ed.), Advances in experimental social psychology, vol. 34 (pp. 331-378). San Diego, CA, US: Academic Press, San Diego, CA.

Kunda, Z. (1990). The case for motivated reasoning. Psychological Bulletin, 108(3), 480498.

Lakoff, G., \& Johnson, M. (1980).The metaphorical structure of the human conceptual system. Cognitive Science: A Multidisciplinary Journal, 4(2), 195-208.

Landau, M. J., Meier, B. P., \& Keefer, L. A. (2010).A metaphor-enriched social cognition. Psychological Bulletin, 136(6), 1045-1067. 
Lavine, H., Lodge, M., \& Freitas, K. (2005). Threat, authoritarianism, and selective exposure to information. Political Psychology. Special Issue: Authoritarianism, 26(2), 219-244.

Lee, S. W. S., \& Schwarz, N. (2010). Dirty hands and dirty mouths: Embodiment of the moral-purity metaphor is specific to the motor modality involved in moral transgression. Psychological Science, 21(10), 1423-1425.

Lee, S. W. S. \& Schwarz, N. (2010b ) Washing away postdecisional dissonance. Science 328, 709.

Lee, S. W. S. \& Schwarz, N. (in press). Metaphor in judgment and decision making. To appear in: M.J. Landau, M. D. Robinson, \& B. P. Meier (Eds.), Metaphorical thought in social life. Washington, DC: American Psychological Association

Loftus, E. F., Greene, E. L., \& Doyle, J. M. (1989).The psychology of eyewitness testimony.In D. C. Raskin (Ed.), Psychological methods in criminal investigation and evidence. (pp. 3-45). New York, NY, US: Springer Publishing Co.

Loftus, E. F., \& Zanni, G. (1975). Eyewitness testimony: The influence of the wording of a question. Bulletin of the Psychonomic Society, 5(1), 86-88.

Lord, C. G. (1989). The "disappearance" of dissonance in an age of relativism. Personality and Social Psychology Bulletin, 15(4), 513-518.

Lord, C. G., Ross, L., \& Lepper, M. R. (1979). Biased assimilation and attitude polarization: The effects of prior theories on subsequently considered evidence. Journal of Personality and Social Psychology, 37(11), 2098-2109. 
Lord, C. G., \& Taylor, C. A. (2009). Biased assimilation: Effects of assumptions and expectations on the interpretation of new evidence. Social and Personality Psychology Compass, 3(5), 827-841.

Mahoney, M. J. (1977) Publication prejudices: An experimental study of confirmatory bias in the peer review system. Cognitive Therapy and Research, 7, 161-17S.

Mead, G. H., Blumer, H., Lakoff, G., Johnson, M., Potter, J., \& Wetherell, M. (2003).Section 2.language and communication. New York, NY, US: Oxford University Press.

Meier, B. P., \& Dionne, S. (2009). Downright sexy: Verticality, implicit power, and perceived physical attractiveness. Social Cognition, 27(6), 883-892.

Meier, B. P., \& Robinson, M. D. (2006). Does "feeling down" mean seeing down? depressive symptoms and vertical selective attention. Journal of Research in Personality, 40(4), 451-461.

Meier, B.P., Schnall, C., Schwarz, N., \& Bargh, J.A. (in press). Embodiment in social psychology. Topics in Cognitive Science.

Miller A. G., McHoskey J. W., Bane C. M., \& Dowd, T. G. (1993). The attitude polarization phenomenon: Role of response measure, attitude extremity, and behavioral consequences of reported attitude change. Jounral Personality and Social Psychology. 64, 561-574.

Miller, D. T., \& Ross, M. (1975). Self-serving biases in the attribution of causality: Fact or fiction? Psychological Bulletin, 82(2), 213-225. 
Mills, J. (1965). Effect of certainty about a decision upon postdecision exposure to consonant and dissonant information. Journal of Personality and Social Psychology, 2(5), 749-752.

Moeller, S. K., Robinson, M. D., \&Z abelina, D. L. (2008). Personality dominance and preferential use of the vertical dimension of space: Evidence from spatial attention paradigms. Psychological Science, 19(4), 355-361.

Munro, G. D., \& Ditto, P. H. (1997). Biased assimilation, attitude polarization, and affect in reactions to stereotyped-relevant scientific information. Personality and Social Psychology Bulletin, 23(6), 636-653.

Munro, G. D., \& Stansbury, J. A. (2009). The dark side of self-affirmation: Confirmation bias and illusory correlation in response to threatening information.Personality and Social Psychology Bulletin, 35(9), 1143-1153.

Myers, D. G., \& Lamm, H. (1976). The group polarization phenomenon. Psychological Bulletin, 83(4), 602-627.

Mynatt, C. R., Doherty, M. E., \& Tweney, R. D. (1977). Confirmation bias in a simulated research environment: An experimental study of scientific inference. The Quarterly Journal of Experimental Psychology, 29(1), 85-95.

Nail, P. R., Misak, J. E., \& Davis, R. M. (2004). Self-affirmation versus self-consistency: A comparison of two competing self-theories of dissonance phenomena.Personality and Individual Differences, 36(8), 1893-1905.

Nickerson, R. S. (1998). Confirmation bias: A ubiquitous phenomenon in many guises. Review of General Psychology, 2(2), 175-220.

Niedenthal, P.M., Krauth-Gruber, S., \& Ric, F. (2004). A role for emotion in lexical 
access. In P. Bonin (Ed.). Mental Lexicon: Some words to talk about words (pp. 147-166). Hauppauge, NY: Nova Science Publishers.

Niedenthal, P. M., Barsalou, L. W., Winkielman, P., Krauth-Gruber, S., \& Ric, F. (2005). Embodiment in attitudes, social perception, and emotion. Personality and Social Psychology Review, 9, 184-211.

Niedenthal, P. M., Winkielman, P., Mondillon, L., \& Vermeulen, N.(2009). Embodiment of emotion concepts. Journal of Personality andSocial Psychology, 96, 1120-1136.

Nisbett, R. E., \& Ross, L. (1980)Human inference:Strategies and shortcomings of social judgement. Englewood Cliffs, NJ: Prentice-Hal

Olson, J. M., \& Stone, J. (2005). In Albarracin D., Johnson B. T. and Zanna M. P. (Eds.), The influence of behavior on attitudes; the handbook of attitudes. Mahwah, NJ, US: Lawrence Erlbaum Associates Publishers, Mahwah, NJ. Oswald, Margit E.; Grosjean, Stefan (2004), Confirmation Bias. In R.F. Pohl, Cognitive Illusions: A Handbook on Fallacies and Biases in Thinking, Judgement and Memory (pp. 79-96), Hove, UK: Psychology Press,

Perkins, D. N., Farady, M., \& Bushey, B. (1991). In Voss J. F., Perkins D. N. and Segal J. W. (Eds.), Everyday reasoning and the roots of intelligence; informal reasoning and education. Hillsdale, NJ, England: Lawrence Erlbaum Associates, Inc, Hillsdale, NJ.

Pomerantz, E. M., Chaiken, S., \& Tordesillas, R. S. (1995). Attitude strength and resistance processes. Journal of Personality and Social Psychology, 69(3), 408-419.

Pompian, M. M. (2006).Behavioral finance and wealth management: how to build optimal portfolios that account for investor biases. New Jersey (NY), John Wiley and Sons. 
Pyszczynski, T., Greenberg, J., Solomon, S., Arndt, J., \& Schimel, J. (2004). Why do people need self-esteem? A theoretical and empirical review. Psychological Bulletin, 130(3), 435-468.

Pyszczynski, T., \& Greenberg, J. (1987). In Berkowitz L. (Ed.), Toward an integration of cognitive and motivational perspectives on social inference: A biased hypothesistesting model; advances in experimental social psychology, vol. 20. San Diego, CA, US: Academic Press, San Diego, CA.

Rassin, E. (2008). Individual differences in the susceptibility to confirmation bias. Netherlands Journal of Psychology, 64(2), 87-93.

Robinson, M. D., Zabelina, D. L., Ode, S., \& Moeller, S. K. (2008). The vertical nature of dominance-submission: Individual differences in vertical attention. .Journal of Research in Personality, 42(4), 933-948.

Rokeach, M. (1960).The open and closed mind: Investigations into the nature of belief system and personality systems. Oxford, England: Basic Books.

Rosenhan, D. L. (2008). On being sane in insane places. In R. Heiner (Ed.), Deviance across cultures. (pp. 235-242). New York, NY, US: Oxford University Press.

Ross, L., Lepper, M. R., \& Hubbard, M. (1975). Perseverance in self-perception and social perception: Biased attributional processes in the debriefing paradigm. Journal of Personality and Social Psychology, 32(5), 880-892.

Sanitioso, R., Kunda, Z., \& Fong, G. T. (1990).Motivated recruitment of autobiographical memories. Journal of Personality and Social Psychology, 59(2), 229-241. 
Schubert, T. W. (2005). Your highness: Vertical positions as perceptual symbols of power. Journal of Personality and Social Psychology, 89(1), 1-21.

Shah, D. V., Cho, J., Eveland, W. P., \& Kwak, N. (2005). Information and expression in a digital age: Modeling internet effects on civic participation.Communication Research, 32(5), 531-565.

Sherman, D. A. K., Nelson, L. D., \& Steele, C. M. (2000). Do messages about health risks threaten the self? increasing the acceptance of threatening health messages via self-affirmation. Personality and Social Psychology Bulletin, 26(9), 1046-1058.

Sherman, G. D., \& Clore, G. L. (2009). The color of sin: White and black are perceptual symbols of moral purity and pollution. Psychological Science, 20(8), 1019-1025.

Sherman, J. W., Allen, T. J., \& Sacchi, D. L. M. (2012). Stereotype confirmation and disconfirmation. In B. Gawronski \& F. Strack (Eds.), Cognitive consistency: A fundamental principle in social cognition (pp. 390-423). New York: Guilford Press.

Shuper, P. A., \& Sorrentino, R. M. (2004). Minority versus majority influence and uncertainty orientation: Processing persuasive messages on the basis of situational expectancies. The Journal of Social Psychology, 144(2), 127-147.

Skitka, L. J., Bauman, C. W., \& Sargis, E. G. (2005). Moral conviction: Another contributor to attitude strength or something more? Journal of Personality and Social Psychology, 88(6), 895-917.

Smith, E. R., \& Semin, G. (2004). In Zanna M. P. (Ed.), Socially situated cognition: Cognition in its social context; advances in experimental social psychology, vol. 36. San Diego, CA, US: Elsevier Academic Press, San Diego, CA. 
Soon, C. S., Brass, M., Heinze, H., \& Haynes, J. (2008).Unconscious determinants of free decisions in the human brain. Nature Neuroscience, 11(5), 543-545.

Sorrentino, R. M., \& Higgins, E. T. (1986). Motivation and cognition: Warming to synergism. In R. M. Sorrentino\& E. T. Higgins (Eds.), The handbook of motivation and cognition: Foundations of social behavior (pp. 3-10). New York: Guilford Press.

Sorrentino, R. M., Bobocel, D. R., Gitta, M. Z., Olson, J. M., \& Hewitt, E. C. (1988). Uncertainty orientation and persuasion: Individual differences in the effects of personal relevance on social judgments. Journal of Personality and Social Psychology, 55(3), 357-371.

Sorrentino, R. M., \& Roney, C. J. R. (1990). In Olson J. M., Zanna M. P. (Eds.), Uncertainty orientation: Individual differences in the self-inference process; self-inference processes: The ontario symposium, vol. 6. Hillsdale, NJ, England: Lawrence Erlbaum Associates, Inc, Hillsdale, NJ.

Sorrentino, R. M., \& Roney, C. J. R. (2000).The uncertain mind: Individual differences in facing the unknown. New York, NY, US: Psychology Press.

Sorrentino, R. M., \& Short, J. C. (1977). The case of the mysterious moderates: Why motives sometimes fail to predict behavior. Journal of Personality and Social Psychology, 35(7), 478-484.

Sorrentino, R. M., \& Short, J. C. (1986). Uncertainty orientation, motivation and cogntion. In R. M. Sorrentino \& E. T. Higgins (Eds.), The handbook of motivation and cognition: Foundations of social behavior (pp. 379-403). New York:

Guilford Press 
Sorrentino, R. M., Short, J. C., \& Raynor, J. O. (1984). Uncertainty orientation:

Implications for affective and cognitive views of achievement behavior. Journal of Personality and Social Psychology, 46(1),

Snyder, M. (1981). Seek and ye shall find: Testing hypotheses about other people. In E. T.Higgins, C. P. Heiman, \& M. P. Zanna (Eds.), Social cognition: The Ontariosymposium on personality and social psychology (pp. 277-303). Hillsdale, NJ:Erlbaum.

Snyder, M., \& Swann, W. B. (1978). Hypothesis-testing processes in social interaction. Journal of Personality and Social Psychology, 36(11), 1202-1212.

Stanovich, K. E, \& West. R. F. (2008). On the relative independence of thinking biases and cognitive ability. Journal of Personality and Social Psychology, 94, 672-695

Steele, C. M. (1988). In Berkowitz L. (Ed.), The psychology of self-affirmation: Sustaining the integrity of the self; advances in experimental social psychology, vol. 21: Social psychological studies of the self: Perspectives and programs. San Diego, CA, US: Academic Press, San Diego, CA.

Steele, C. M., Spencer, S. J., \& Lynch, M. (1993). Self-image resilience and dissonance: The role of affirmational resources. Journal of Personality and Social Psychology, 64(6), 885-896.

Strack, F., Martin, L. L., \& Stepper, S. (1988). Inhibiting and facilitating conditions of the human smile: A nonobtrusive test of the facial feedback hypothesis. Journal of Personality and Social Psychology, 54(5), 768-777. 
Strangor, C., \& McMillan, D. (1992). Memory for expectancy-congruent and expectancyincongruent information: A review of the social and social developmental literatures. Psychological Bulletin, 111, 42-61.

Sunstein, C. R. (2007). Group polarization and 12 angry men. Negotiation Journal, 23(4), 443-447.

Swann, W. B., \& Read, S. J. (1981).Acquiring self-knowledge: The search for feedback that fits. Journal of Personality and Social Psychology, 41(6), 1119-1128.

Swann, W. B., Pelham, B. W., \& Krull, D. S. (1989).Agreeable fancy or disagreeable truth? reconciling self-enhancement and self-verification. Journal of Personality and Social Psychology, 57(5), 782-791.

Taber, C. S., and Lodge, M. (2006). Motivated Skepticism in the Evaluation of Political Beliefs.American Journal of Political Science, 50, 755-769

Taylor, S. E., \& Brown, J. D. (1988). Illusion and well-being: A social psychological perspective on mental health. Psychological Bulletin, 103(2), 193-210.

Tesser, A. (2000). On the confluence of self-esteem maintenance mechanisms. Personality and Social Psychology Review, 4(4), 290-299.

Tesser, A., Crepaz, N., Beach, S. R. H., Cornell, D., \& Collins, J. C. (2000). Confluence of self-esteem regulation mechanisms: On integrating the self-zoo.Personality and Social Psychology Bulletin, 26(12), 1476-1489.

Tetlock, P. E. (1985). Accountability: The neglected social context of judgment and choice. Research in Organizational Behavior, 7, 297-332. 
Tetlock, P. E. (1992). In Zanna M. P. (Ed.), The impact of accountability on judgment and choice: Toward a social contingency model; advances in experimental social psychology, vol. 25. San Diego, CA, US: Academic Press, San Diego, CA.

Thelen, E., Schoner, G., Scheier, C., \& Smith, L. B. (2001). The dynamics of embodiment: A field theory of infant perseverative reaching. Behavioral and Brain Sciences, 24(1), 1-86.

Trope, Y., \& Ben-Yair, E. (1982).Task construction and persistence as means for selfassessment of abilities. Journal of Personality and Social Psychology, 42(4), 637645.

Trope, Y., \& Liberman, A. (1996). In Higgins E. T., Kruglanski A. W. (Eds.), Social hypothesis testing: Cognitive and motivational mechanisms; social psychology: Handbook of basic principles. New York, NY, US: Guilford Press, New York, NY.

Trope, Y., \& Pomerantz, E. M. (1998).Resolving conflicts among self-evaluative motives: Positive experiences as a resource for overcoming defensiveness. Motivation and Emotion, 22(1), 53-72.

Tversky, A., \& Kahneman, D. (1974). Judgment under uncertainty: Heuristics and biases. Science, 185(4157), 1124-1131.

Tweney, R. D., Doherty, M. E., Worner, W. J., Pliske, D. B., Mynatt, C. R., Gross, K. A., \& Arkkelin, D. L. (1980).Strategies of rule discovery in aninference task.Quarterly Journal of ExperimentalPsychology, 32, 109-123.

VanVeen, V., Krug, M. K., Schooler, J. W., \& Carter, C. S. (2009). Neural activity predicts attitude change in cognitive dissonance. Nature Neuroscience, 12(11), 14691474. 
vonHippel, W., Lakin, J. L., \& Shakarchi, R. J. (2005). Individual differences in motivated social cognition: The case of self-serving information processing. Personality and Social Psychology Bulletin, 31(10), 1347-1357.

Wason, P. C. (1960). On the failure to eliminate hypotheses in a conceptual task. The Quarterly Journal of Experimental Psychology, 12, 129-140.

Wason, P. C. (1968). Reasoning about a rule. The Quarterly Journal of Experimental Psychology, 20(3), 273-281.

Weiner, B. (1972). Attribution theory, achievement motivation, and the educational process. Review of Educational Research, 42(2), 203-215.

Wells, G. L., \& Petty, R. E. (1980). The effects of overt head movements on persuasion: Compatibility and incompatibility of responses. Basic and Applied Social Psychology, 1(3), 219-230. 2

West, R, F., Meserve, R. J., \& Stanovich, K. E., (2012). Cognitive sophistication does not attenuate the bias blind spot. Journal of Personality and Social Psychology

Westen, D., Blagov, P. S., Harenski, K., Kilts, C., \& Hamann, S. (2006). Neural bases of motivated reasoning: An fMRI study of emotional constraints on partisan political judgment in the 2004 U.S. presidential election. Journal of Cognitive Neuroscience, 18(11), 1947-1958.

Whittlesea, B. W. A. (1993). Illusions of familiarity. Journal of Experimental Psychology: Learning, Memory, and Cognition, 19(6), 1235-1253.

Williams, L. E., \& Bargh, J. A. (2008a). Experiencing physical warmth promotes interpersonal warmth. Science, 322(5901), 606-607. 
Williams, L. E., \& Bargh, J. A. (2008b). Keeping one's distance: The influence of spatial distance cues on affect and evaluation. Psychological Science, 19(3), 302-308.

Wilson, M. (2002). Six views of embodied cognition. Psychonomic Bulletin \& Review, 9(4), 625-636.

Wilson, T. D., Centerbar, D. B., \& Brekke, N. (2002). In Gilovich T., Griffin D. and Kahneman D. (Eds.), Mental contamination and the debiasing problem; heuristics and biases: The psychology of intuitive judgment. New York, NY, US: Cambridge University Press, New York, NY. Retrieved

Xu, A. J., Zwick, R., \& Schwarz, N. (2011). Washing away your (good or bad) luck: Physical cleansing affects risk-taking behavior. Journal of Experimental Psychology: General,

Zanna, M. P., \& Cooper, J. (1974). Dissonance and the pill: An attribution approach to studying the arousal properties of dissonance. Journal of Personality and Social Psychology, 29(5), 703-709.

Zhong, C., \& Liljenquist, K. (2006). Washing away your sins: Threatened morality and physical cleansing. Science, 313(5792), 1451-1452. 


\section{Appendix A \\ $n$ Uncertainty - Thematic Apperception Test}

\section{Instructions:}

You are going to see a series of sentences, and your task is to tell a story that is suggested to you by each sentence. Try to imagine what is going on. Then tell what the situation is, what led up to the situation, what the people are thinking and feeling, and what they will do.

In other words, write as complete a story as you can--a story with plot and characters.

You will have twenty (20) seconds to look at a sentence and then 4 minutes to write your story about it. Write your first impressions and work rapidly. I will keep time and tell you when it is time to finish your story and to get ready for the next sentence.

There are no right or wrong stories or kinds of stories, so you may feel free to write whatever story is suggested to you when you look at a sentence. Spelling, punctuation, and grammar are not important. What is important is to write out as fully and as quickly as possible the story that comes into your mind as you imagine what is going on.

Sentence Leads:

a) Two people are working in a laboratory on a piece of equipment;

(b)A person is sitting, wonder what may happen;

(c)A person is seated at a desk with a computer and books;

(d) An older person is talking to a young person.

\section{Questions}

1. What is happening? Who is (are) the person(s)

2. What has led up to this situation? That is, what has happened in the past?

3. What is being thought? What is wanted? By whom?

4. What will happen? What will be done? 


\section{Appendix B}

Authoritarianism F- scale

+1: I AGREE A LITTLE

+2: I AGREE SOMEWHAT

+3: I AGREE VERY MUCH
-1: I DISAGREE A LITTLE

-2: I DISAGREE SOMEWHAT

-3: I DISAGREE VERY MUCH

1. There is hardly anything lower than a person who does not feel a great love, gratitude and respect for his or her parents.

$$
\begin{array}{llllll}
+3 & +2 & +1 & -1 & -2 & -3
\end{array}
$$

2. An insult to our honour should always be punished.

$$
\begin{array}{llllll}
+3 & +2 & +1 & -1 & -2 & -3
\end{array}
$$

3. Books and movies ought not to deal so much with the unpleasant and seamy side of life; they ought to concentrate on themes that are entertaining or uplifting.

$$
\begin{array}{llllll}
+3 & +2 & +1 & -1 & -2 & -3
\end{array}
$$

4. What the youth needs most is strict discipline, rugged determination, and the will to work and fight for family and country.

$$
\begin{array}{llllll}
+3 & +2 & +1 & -1 & -2 & -3
\end{array}
$$

5. No sane, normal, decent person could ever think of hurting a close friend or relative.

$$
+3 \quad+2 \quad+1 \quad-1 \quad-2 \quad-3
$$

6. Young people sometimes get rebellious ideas, but as they grow up they ought to get over them and settle down.

$$
\begin{array}{llllll}
+3 & +2 & +1 & -1 & -2 & -3
\end{array}
$$

7. The findings of science may someday show that many of our most cherished beliefs are wrong.

$$
\begin{array}{llllll}
+3 & +2 & +1 & -1 & -2 & -3
\end{array}
$$


8. People ought to pay more attention to new ideas, even if they seem to go against the Canadian way of life.

$$
+3 \quad+2 \quad+1 \quad-1 \quad-2 \quad-3
$$

9. If people would talk less and work more everybody would be better off.

$$
+3 \quad+2 \quad+1 \quad-1 \quad-2 \quad-3
$$

10. A person who has bad manners, habits, and breeding can hardly expect to get along with decent people.

$$
+3 \quad+2 \quad+1 \quad-1 \quad-2 \quad-3
$$

11. Insults to our honour are not always important enough to bother about.

$$
+3 \quad+2 \quad+1 \quad-1 \quad-2 \quad-3
$$

12. It is right for people to raise questions about even the most sacred matters.

$$
+3 \quad+2 \quad+1 \quad-1 \quad-2 \quad-3
$$

13. Obedience and respect for authority are the most important virtues children should learn.

$$
+3 \quad+2 \quad+1 \quad-1 \quad-2 \quad-3
$$


14. There is no reason to punish any crime with the death penalty.

$$
\begin{array}{llllll}
+3 & +2 & +1 & -1 & -2 & -3
\end{array}
$$

15. Anyone who would interpret the Bible literally just doesn't know much about geology, biology, or history.

$$
\begin{array}{llllll}
+3 & +2 & +1 & -1 & -2 & -3
\end{array}
$$

16. In this scientific age the need for a religious belief is more important than ever before.

$$
\begin{array}{llllll}
+3 & +2 & +1 & -1 & -2 & -3
\end{array}
$$

17. When they are little, kids sometimes think about doing harm to one or both of their parents.

$$
\begin{array}{llllll}
+3 & +2 & +1 & -1 & -2 & -3
\end{array}
$$

18. It is possible that creatures on other planets have founded a better society than ours.

$$
+3 \quad+2 \quad+1 \quad-1 \quad-2 \quad-3
$$

19. The prisoners in our corrective institutions, regardless of the nature of their crimes should be treated humanely.

$$
\begin{array}{llllll}
+3 & +2 & +1 & -1 & -2 & -3
\end{array}
$$

20. The sooner people realize that we must get rid of all traitors in the government, the better off we'll be.

$$
\begin{array}{llllll}
+3 & +2 & +1 & -1 & -2 & -3
\end{array}
$$

21. Some of the greatest atrocities in history have been committed in the name of religion and morality.

$$
\begin{array}{llllll}
+3 & +2 & +1 & -1 & -2 & -3
\end{array}
$$




\section{Appendix C}

What is your ethnicity?

Place of birth: (what country were you born in)?

What is your first language?

How old are you?

Are you Male or Female Male Female

What is your Religion?

How religious are you?

1 (Not Religious at all)

2 (Slightly Religious)

3 (Moderately Religious)

4 (Quite Religious)

5 (Very Religious)

Do you consider yourself Right-wing, or Left-wing 1 (Left-wing) 2 (Right Wing) 3( Neither) 
Appendix D

4 x 4 Information Matrix

\section{Please click on a cell to open an argument}

Source of Infarmation

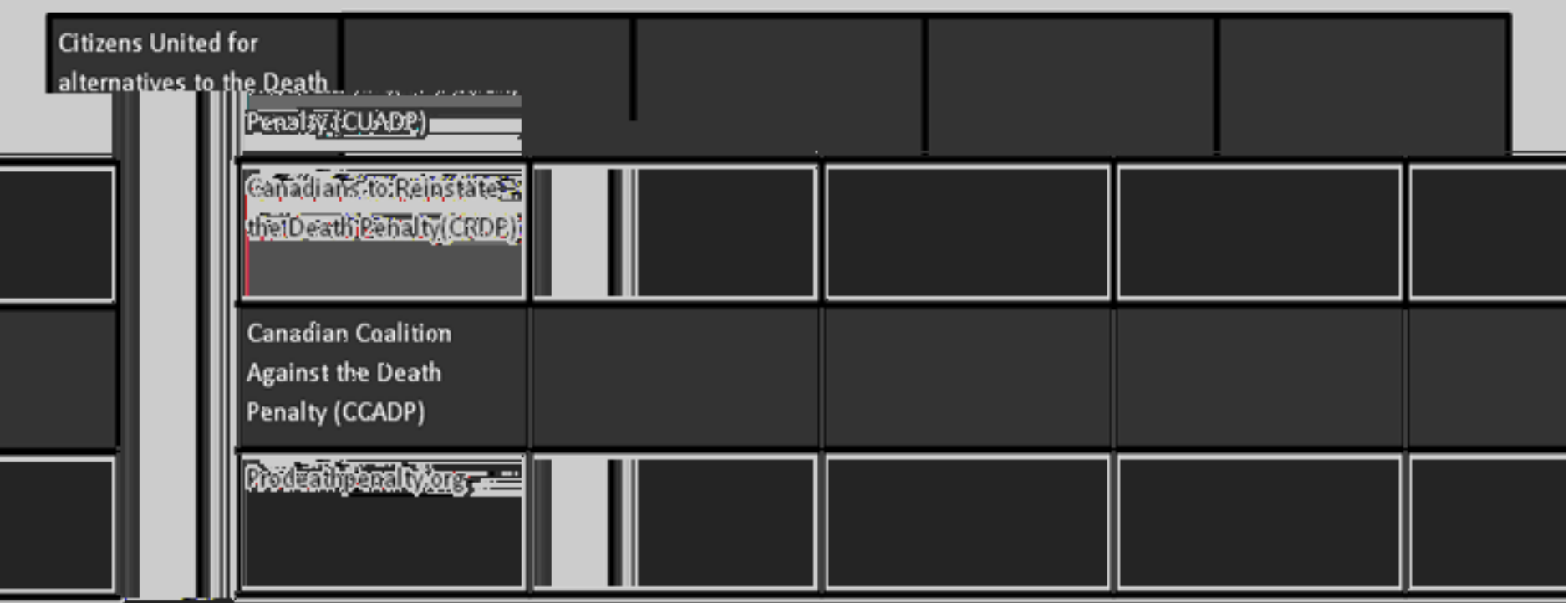




\title{
Appendix E
}

\section{Same-sex Marriage}

\author{
List of Arguments For Each Topic
}

\section{$\underline{\text { In favour }}$}

Denying same sex marriage on the basis of religious grounds is a violation of religious freedoms. Civil Law and religious opinions must remain kept separate.

Marriage benefits, such as joint ownership, medical decision-making capacity, should be available to all couples.

Homosexuality is an accepted lifestyle nowadays with most evidence strongly supporting biological causation.

Denying these marriages is a form of minority discrimination.

It doesn't hurt society or anyone in particular.

The only thing that should matter in marriage is love.

The number of child adoptions should increase since same-sex couples cannot pro-create It encourages people to have strong family values and give up high-risk sexual lifestyles. 


\section{Same-sex Marriage}

\section{$\underline{\text { Against }}$}

Marriages are for ensuring the continuation of the species.

The same-sex lifestyle is not something to be encouraged, as a lot of research shows it leads to a much lower life expectancy, psychological disorders, and other problems.

Same-sex marriage is bad for the children. Children have been raised by a man and woman for thousands of years and allowing same sex marriages would be an untried social experiment

Leaders of religious faiths (i.e. Pastors, Rabbis, etc.) would be forced to marry people, even if it conflicted with their religious beliefs.

Same-sex relationships are immoral and violate the sacred institution of marriage according to many religions

It weakens the definition and respect for the institution of marriage.

It weakens the traditional family values essential to our society.

It provides a slippery slope in the legality of marriage (e.g. having multiple wives or marrying an animal could be next). 


\section{Employment Equity}

In favour

Some whites claim to be victims of Employment Equity programs. Nonsense! White Canadians have long benefited from a society biased toward white interests, so any current preferences for minorities are only fair. There are no victims of Employment Equity. Therefore, we should all support Employment Equity programs.

The largest group of Canadians to benefit from Employment Equity thus far are women. Before 1964, women were excluded from many higher paying occupations and professions based on stereotype, custom and law. There were virtually no women police officers, lawyers, or doctors, for example. Progress has been made, but women still need Employment Equity programs.

Nothing in the Constitution prohibits Employment Equity. In fact, the Supreme Court upheld Employment Equity programs in education in a landmark case. In this case, the Court explicitly stated that "Employment Equity is consistent with the Constitution.

Who says racism is dead in America? Far from it. Surveys show that a majority of white Canadians still believe that African- and Latino Canadians are less intelligent, less hard working and less patriotic than whites. Employment Equity programs are an important step toward changing these racist attitudes.

When a company with a history of past discrimination passes over a white man and hires a qualified minority or woman instead, that isn't "reverse discrimination." When black professional athletes were first hired, breaking the "color barrier" in sports, some white ballplayers lost job opportunities. But that was not "reverse discrimination," it was a first step toward ending discrimination.

In the historic words of one Canadian leader, "America has given the Negropeople a bad check marked insufficient funds." It is about time that Canada makes good on its promise of opportunity for all. Employment Equity programs are a necessary first step toward racial equality in America.

In 1990 , the average black male worker earned just $\$ 731$ for every $\$ 1,000$ earned by a white male worker in a comparable position. Moreover, though white males make up only $43 \%$ of the workforce, they occupy $97 \%$ of Canada's top executive positions. After decades of discrimination, only tough Employment Equity programs can level the playing field.

Employment Equity programs are very effective. A study from the Clinton administration shows that the percentage of blacks entering the fields of law and medicine has increasedfrom less than $2 \%$ to over $10 \%$ in the past 20 years. Employment Equity is working. 


\section{Employment Equity}

\section{$\underline{\text { Against }}$}

Employment Equity plans treat people based on race, not past or present circumstances. Middle class blacks are given preferences while lower class whites are not! This is unfair reverse discrimination and is itself a form of racism. Employment Equity programs must stop.

Many of the victims of Employment Equity are Asian-Canadians who have been excluded from top schools due to racial quotas. But they had no role at all in the country's history of discrimination against blacks and they are truly innocent victims! Employment Equity programs are doing more harm than good.

According to a prominent African-Canadian economist, under Employment Equity, blacks often get admitted into schools and programs even though they have worse credentials than most white applicants. As a result, their dropout rate is higher. Employment Equityplans harm both blacks and whites and should be stopped.

The Constitution absolutely prohibits racial discrimination, including Employment Equity. As one landmark case declared, "our Constitution is color-blind, and neither knows nor tolerates classes among citizens." Therefore, Employment Equity plans are unconstitutional.

The preeminent African-American leader of all time put it best: "Men should be judged by the content of their character, not the color of their skin." Clearly this statement recognizes the injustice of any form of racial preferences. In other words, even one of the most famous black leaders in history is opposed Employment Equity!

Merit has always been the most important factor determining success in this country. People of all races and classes can get ahead if they are willing to work. Unfortunately, some Canadians expect to be handed a free lunch. Opportunities exist for all, but you have to be willing to pull your weight. Employment Equity violates the merit principle and should be ended.

In a recent national poll, 50\% of Canadians said they oppose Employment Equity. It seems that most of our laws these days favour minorities, and Canadians are getting fed up. If a majority of Canadian citizens believe that Employment Equity programs are unfair, then why have these laws not been repealed? End Employment Equity now!

Employment Equity programs at Canadian universities "stigmatize" African Canadians and other minority students who are assumed to be incompetent because they were admitted based on color, not on merit. Individuals, whether black or white, are far more likely to be successful if they prove their abilities in equal competition rather than receiving unfair and unearned advantages. Employment Equity works to the disadvantage of minorities. 


\section{Abortion}

\section{Pro-Life}

Abortion is a form of murder and demeans the value of human life.

Other birth control is readily available; thus, abortion shouldn't be a form of birth control.

The societal contributions of a potentially valuable human being are wiped out.

Women who have abortions and the father of the child often suffer major psychological damage from the experience.

The advances of genetic testing may lead to parents simply abortion babies for inconsequential reasons like hair colour.

There are many couples who spend years on waiting lists trying to adopt a child.

The abortion decision is often made by minors or young adults, who don't have the maturity and life experiences to make good decisions.

People have the right not to see their tax dollars go to something they find immoral 


\section{Abortion}

Pro-choice

Abortion laws would allow the government to enforce laws over how woman control their bodies

If Abortion was illegal "Back alley" abortions would increase if it were made illegal, leading to increased risk of young women dying or becoming sterile.

It's arguably better for society to have babies aborted than have them be brought up poor and neglected, where not only will the child suffer but society when that child develops a higher attraction to crime, welfare, etc.

A pregnancy could be only one mistake and could force a woman into a situation she does not want to be in which will affect both her and her child.

Abortion is not murder because it is performed before a fetus has developed cognitive abilities.

Having to give a baby up for adoption is more emotionally damaging than abortion.

Pregnancy can be a medical risk. It is not fair to force a woman to undergo such a risk.

Some women who get pregnant are not mature enough to have a child as often they are just children themselves. We should allow everyone to have a full life and mature before having children. 


\section{Capital Punishment}

\section{$\underline{\text { In Favour }}$}

DNA testing and other methods of modern crime scene science can now effectively eliminate almost all uncertainty as to a person's guilt or innocence.

Capital punishment permanently removes the worst criminals from society and from the prison system and is therefore much safer for us than long term or permanent incarceration.

It helps eliminate the problem of overpopulation in the prison system.

It gives prosecutors another bargaining chip in the plea bargain process, which is essential in cutting costs in an overcrowded court system.

The death penalty gives closure to the victim's families who have suffered so much.

Capital punishment is the best form of crime deterrent

Our justice system shows more sympathy for criminals than criminals do their victims.

It provides a deterrent for prisoners already serving a life sentence. 


\section{Capital Punishment}

\section{$\underline{\text { Against }}$}

Financial costs to taxpayers of capital punishment are several times that of keeping someone in prison for life.

It is barbaric and violates the "cruel and unusual" clause in the Bill of Rights.

The endless appeals and required additional procedures clog our court system.

We as a society have to move away from the "eye for an eye" revenge mentality if civilization is to advance.

It sends the wrong message: How can we justify murder as a punishment for murder?

Life in prison is a worse punishment and a more effective deterrent.

Other countries (especially in Europe) would have a more favourable image of Canada.

Some jury members are reluctant to convict if it means putting someone to death. 


\section{Appendix F: Matrix Instructions}

In the following task you will be shown a 4 x 4 Matrix. Two of the rows contain arguments from associations that are for (same-sex marriage) and two rows contain arguments from associations that are against (same-sex marriage). Please take this time to become familiar with the matrix (Matrix was shown).

You will be allowed to choose 8 boxes. You may choose any 8 you wish in any order you would like.

Prior to this activity, the experimenter showed you a hand motion. We would like you to mimic this action while you are thinking about which box to choose. A yellow display box will be presented with the words "Please mimic the hand motion until this disappears." Please continue mimicking the hand motion for the duration of the yellow box.

We would like you to also do the motion while you are reading the argument you have chosen.

Remember, you will be allowed to choose 8 boxes and may choose any 8 in any order you would like.

When you are ready please click continue 


\section{Appendix G}

Matrix with Embodiment Manipulation Prompt

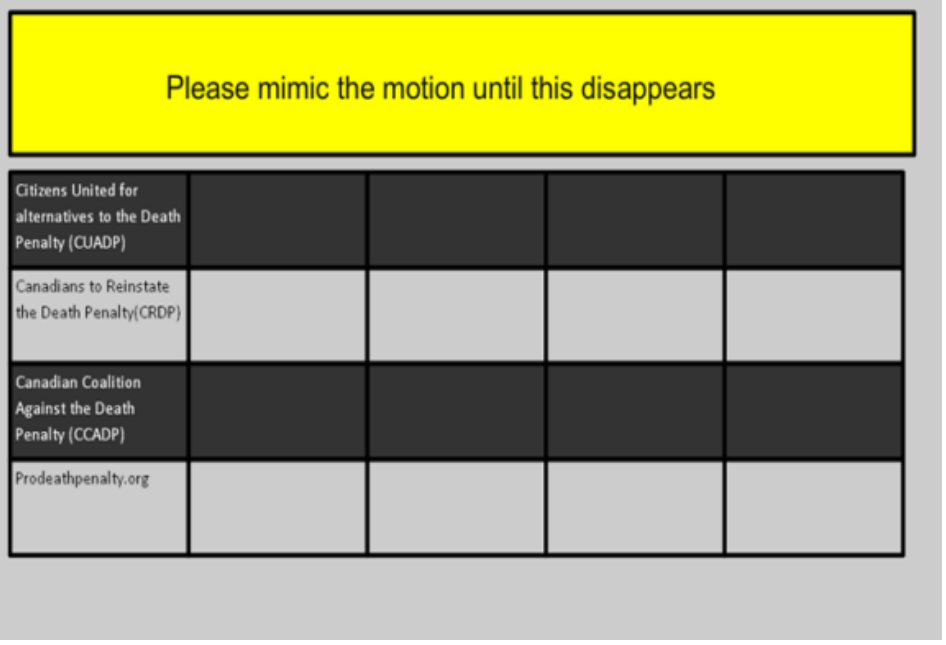


Appendix $\mathrm{H}$

Argument Example

Please mimic the hand motion while reading the following argument:

Financial costs to taxpayers of capital punishment are several times that of keeping someone in prison for life. 
Appendix I

Argument Rating Example

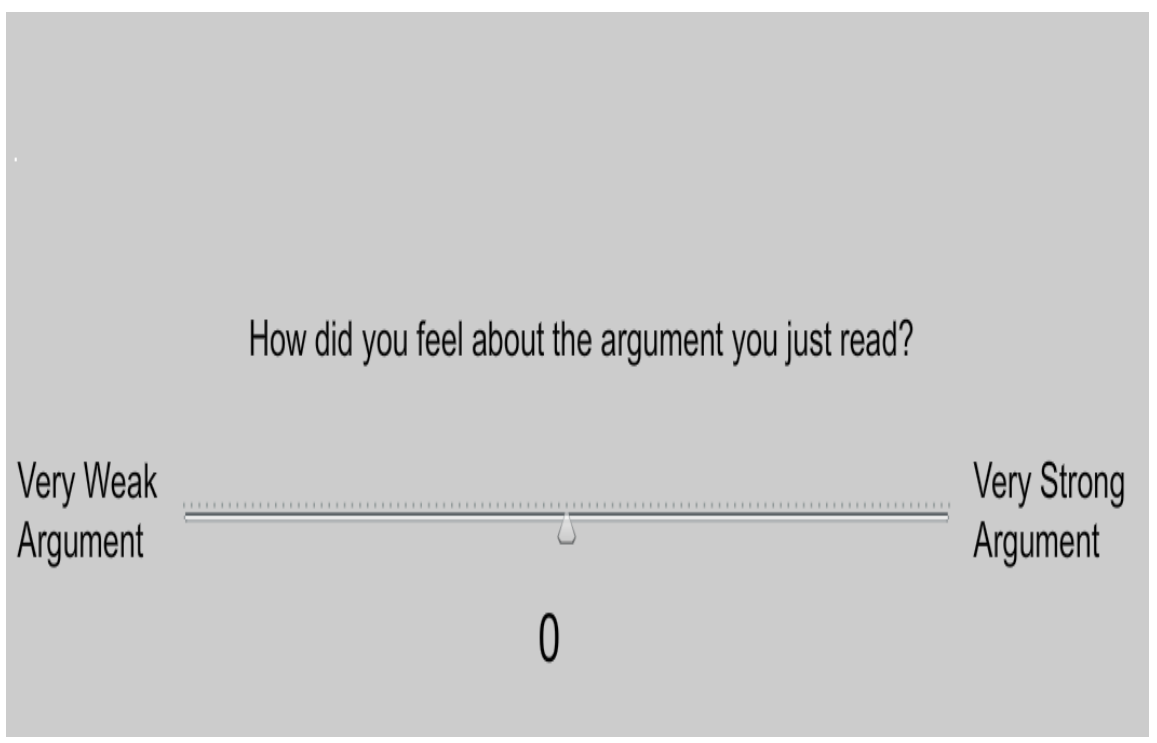


Appendix J

Matrix Argument Selection:

Example Prior to Selecting the Fourth Argument

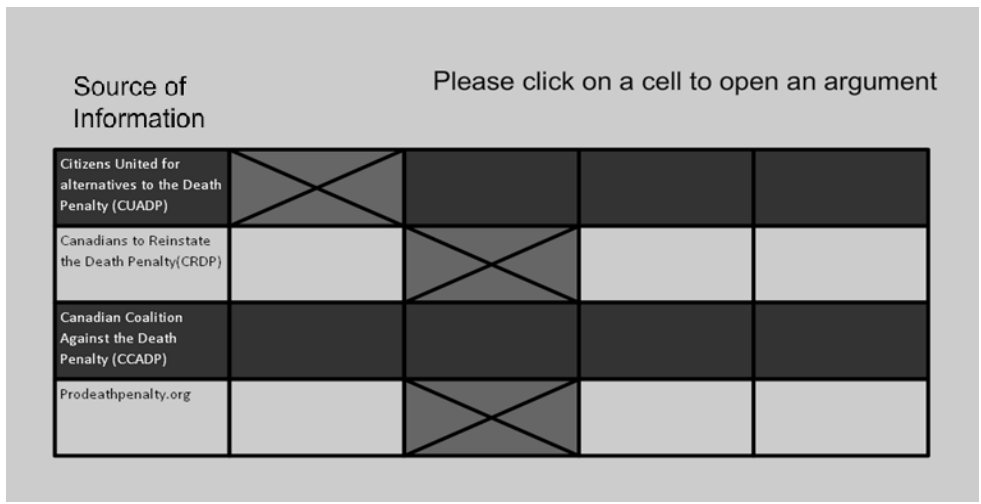


Appendix K

Topic Selection

Which of these four issues below do you feel is most important to you?

\section{1) Abortion}

2) Employment Equity/

Affirmative Action

3) Capital Punishment

4) Same-Sex Marriage 


\title{
Appendix L: Ethics Approval Form
}

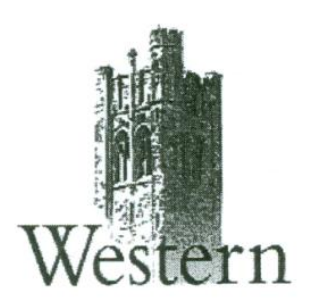

\author{
Department of Psychology The University of Western Ontario \\ Room 7418 Social Sciences Centre, \\ London, ON, Canada N6A 5C1 \\ Telephone: (519) 661-2067Fax: (519) 661-3961
}

\begin{tabular}{|r|l|r|l}
\hline Review Number & 110944 & Approval Date & 110930 \\
\hline Principal Investigator & Richard Sorrentino/Shelby Wilson/Jeff Rotman/Yang Ye & End Date & 120430 \\
\hline Protocol Title & How does attention influence our thoughts and behaviour? \\
\hline Sponsor & n/a
\end{tabular}

This is to notify you that The University of Western Ontario Department of Psychology Research Ethics Board (PREB) has granted expedited ethics approval to the above named research study on the date noted above.

The PREB is a sub-REB of The University of Western Ontario's Research Ethics Board for Non-Medical Research Involving Human Subjects (NMREB) which is organized and operates according to the Tri-Council Policy Statement and the applicable laws and regulations of Ontario. (See Office of Research Ethics web site: http://www.uwo.ca/research/ethics/)

This approval shall remain valid until end date noted above assuming timely and acceptable responses to the University's periodic requests for surveillance and monitoring information.

During the course of the research, no deviations from, or changes to, the protocol or consent form may be initiated without prior written approval from the PREB except when necessary to eliminate immediate hazards to the subject or when the change(s) involve only logistical or administrative aspects of the study (e.g. change of research assistant, telephone number etc). Subjects must receive a copy of the information/consent documentation.

Investigators must promptly also report to the PREB:

a) changes increasing the risk to the participant(s) and/or affecting significantly the conduct of the study;

b) all adverse and unexpected experiences or events that are both serious and unexpected;

c) new information that may adversely affect the safety of the subjects or the conduct of the study.

If these changes/adverse events require a change to the information/consent documentation, and/or recruitment advertisement, the newly revised information/consent documentation, and/or advertisement, must be submitted to the PREB for approval.

Members of the PREB who are named as investigators in research studies, or declare a conflict of interest, do not participate in discussion related to, nor vote on, such studies when they are presented to the PREB.

\section{Clive Seligman Ph.D.}

Chair, Psychology Expedited Research Ethics Board (PREB)

The other members of the 2011-2012 PREB are: Mike Atkinson (Introductory Psychology Coordinator), Rick Goffin, Riley Hinson Albert Katz (Department Chair), Steve Lupker, and TBA (Graduate Student Representative) 


\section{Curriculum Vitae}

\section{Jeff Rotman}

\section{Education and Degrees}

Masters of Science, Social Psychology (in progress) University of Western Ontario.

Honours, Bachelor of Science, Psychology. Minor in Biology, University of Guelph (2009)

\section{Publications}

Rotman, J., Ye, Y., Sorrentino, R., Szeto, A., Dalke, K., Yoshida, E. (2012) Uncertainty Orientation and the Influence of Implicit Cultural Norms versus Personal Attitudes on Eating Behavior. MindPad, 1, 16-20

\section{Conference Presentations and Posters}

Rotman, J., Ye, Y., Sorrentino, R. (2012) On the One Hand , and on the Other: The Effect of Embodying Balance and Uncertainty Orientation on the Confirmation Bias. Poster presented at the Annual meeting for the Society for the Study of Motivation (SSM), Chicago, Il, May $24^{\text {th }}$, 2012.

Rotman, J., Ye, Y., Sorrentino, R. (2012) On the One Hand, and on the Other: The Effect of Embodying Balance and Uncertainty Orientation on the Confirmation Bias. Poster presented at the Annual Western-Waterloo Conference for Social Psychology, London, On, May 10 ${ }^{\text {th }}, 2012$.

Rotman, J., Ye, Y., Sorrentino, R., Szeto, A. (2012)Uncertainty Orientation and the Influence of Implicit Cultural Norms versus Personal Attitudes on Eating Behavior. Poster presented for Society of Personality and Social Psychology, San Diego, California, January 26-28, 2012

Rotman, J., Esses, V., That's So Gay: (2012) This Poster Is So Gay: .The Relation Between Attitudes Towards Homosexuals and The Use of the Expression 'That's so Gay' Poster presented for the Society of Personality and Social Psychology, San Diego, California, January 26-28, 2012

Yang, Y., Rotman, J., Sorrentino, R., Dalke, K., Szeto, A. (2012) The Effects of Uncertainty Orientation and the Priming of Feeling versus Knowing on Attitudes towards Canadians and Americans, Poster presented for Society of Personality and Social Psychology, San Diego, California, January 26-28, 2012.

Rotman, J., Meegan, D. (2009) The Effects of Reconsolidation on Negative Transfer and Proactive Interference in Humans. Paper presented at the Undergraduate Thesis Conference, Guelph, Ontario, April 14 2009.

Milhausen, R. R., Sakaluk, J., Todd, L., Rotman, J., Lachowsky, N., LeBlanc, L., Spring, L., Morrow, E., Laroque, A., and the Undergraduate Research Group in Sexuality. Booty calls, friends with benefits, and fuck buddies: The new "rules" for casual sex among Canadian university students. Paper presented at the Annual Meeting of the Society for the Scientific Study of Sexuality's Annual Meeting, San Juan, Puerto Rico, November 5-9, 2008.

\section{Awards, Honours, and Research Funding}

Ontario Graduate Scholarship, Government of Ontario, (2011-2012) Value: \$15,000.

Nominated for Graduate Student Teaching Award (2011 \& 2012)

Joseph-Armand Bombardier grant, SSHRC (2010 - 2011) Value: \$17,500 